\title{
Between Livestock's and Humans, Q Fever Disease is Emerging at Low Noise
}

\author{
Ghaoui $\mathrm{H}^{1,2,3 *}$, Achour $\mathrm{N}^{3}$, Saad-Djaballah $\mathrm{A}^{3}$, Smai $\mathrm{A}^{2}$, Temim $\mathrm{S}^{2}$ and Bitam $\mathrm{I}^{4,5}$ \\ ${ }^{1} I R D, M E P H I$, Aix-Marseille Université, IHU Méditerranée Infection, Marseille, France \\ ${ }^{2}$ Ecole Nationale Supérieure Vétérinaire d'Alger, RABIE BOUCHAMA, Alger, Algeria \\ ${ }^{3}$ EHS des maladies infectieuses ELHADI FLICI Alger, Algeria \\ ${ }^{4}$ Ecole Supérieure en Sciences de l'Aliment et des Industries Agroalimentaire d'Alger, Algeria \\ ${ }^{5}$ IRD, VETROM, Aix-Marseille Université, IHU Méditerranée Infection, Marseille, France
}

*Corresponding Author: Ghaoui H, IRD, MEPHI, Aix-Marseille Université, IHU Méditerranée Infection, Marseille, France.

Received: August 01, 2019; Published: September 20, 2019

\begin{abstract}
Coxiella burnetii is the pathogenic agent of the $\mathrm{Q}$ fever which remains a worldwide zoonotic disease. The natural cycle of this bacterium is not reported to include humans, who are considered incidental hosts. The true reservoir is wide and includes mammals, birds and arthropods mainly tick. $Q$ fever is most often contracted after human inhalation of infected dusts particles, handle infected animal tissues, such as urine, faeces or birth products. Person-to-Person transmission is rare but it has been documented. However, Coxiella burnetii has been identified in the semen of infected males, and this has resulted in sexual transmission of the pathogen. Acute or chronic Coxiella burnetii infection exhibits a wide spectrum of clinical manifestations; roughly 50\% of all infections with Coxiella burnetii are asymptomatic, and can lead also to an unexplained pyrexia that makes diagnosis difficult for infectious disease specialists. Following inhalation, symptoms can develop after 10 to 90 days, depending on the dose. Coxiella burnetii has been flagged where it has been searched for. Due to the epidemiological surveys in most developed countries, clear pictures about exposure factors, hosts-reservoirs life cycle are amply described, hence its incidence is generally quite low.
\end{abstract}

Keywords: Q Fever; Zoonosis; Coxiella burnetii; Outbreaks; Description; Bio-Threat

\section{Abbreviations}

CDC: Centers of Disease Control and Prevention; USA: United States of America; VNTR: Variable-Number Tandem Repeat; MLVA: Multilocus Variable-Number Analysis; MST: Multispacer Sequence Typing; SNP: Single Nucleotide Polymorphism; UK: United Kingdom; NAME: Numerical Atmospheric-dispersing Modelling Environment; DNA: Deoxyribonucleic Acid; RNA: Ribonucleic Acid; TESSy: The Europrean Surveillance System; IFA: Immunofluorescence Assay; PCR: Polymerase-Chain-Reaction; WHA: Third World Health Assembly; USAF: United State Air Force; WHO: World Health Organization; IgG: Immunoglbuline G; IgM: Immunoglobuline M; IgA : Immunoglobuline A; ELISA: Enzyme Linked Immunosorbent Assay; CFT: Complement Fixation Test; pH: Potential Hydrogen; LCV: Large-Cell Variant; SCV: Small-Cell Variant; ACCM2: Axenic Acidified Cysteine Citrate Medium 2; LPS: Lipopolysaccharide; VCC: Vacuole Containing Coxiella; LC3: Microtubule-Associated Protein Light-Chain 3; EEAI: Early Endosomal Marker Protein; IAP: Integrin Associated Protein; TLR4: Toll-like Receptor 4; CD4: Cluster Differentiation 4; CD8: Cluster Differentiation 8; aCL: anti-Cardio- lipin; VHD: Valvular Heart Disease; CSF: Cerebrospinal Fluid; MRI: Magnetic Resonance Imaging; AUS: Abdominal Ultrasonography; ESR: Erythrocyte Sedimentation Rate; QFS: Post-Q Fever Fatigue Syndrome; EDTA: Acid Ethylene-Diamine-Tetra-Acetic; IHU : Institut Hospitalo-Universitaire; PBS : Phosphate -Buffered Saline; IFN $_{\gamma}$ : Interferon ${ }_{\gamma}$; CMR: Chloroform Methanol Residue.

\section{Introduction}

Undeniably, infectious diseases remain the sphere the most important in the recent decades. The balance between old and new infections, has never tilted to one side. Constantly, new infections diseases appear, and the old ones emerge. Through the studied past, $75 \%$ of the re-emerging infectious diseases are zoonosis. This fact may be linked to the high sensitive relationship between HostPathogen, which are knowing several phenotypical and genotypic changes, thus acquiring new characteristics and arise in unexpected environments or food vehicles. All these changes, may be caused by climate shifts, and their environmental impacts on biodiversity that has affected the howl world. 
Q Fever, zoonosis disease, since it discovery, it attracted a special attention where ever it was flagged. New advances and knowledge's about Coxiella burnetii the causative agent of the disease, gave it more importance. The variable clinical manifestation, intracellular cycle life, and also to its genomic plasticity, put the diagnosticians in constant debate. Over time, and places, Q Fever outbreaks have prompted the countries concerned to develop control and preventive measures to deal with its potential repercussions on public health, livestock and economy. In 2003, the CDC, classified it as bioterrorism agent category B, this allowed a lot of ink to flow on Coxiella burnetii, and raises the barrier of epidemiosurveillance across all countries of the world.

In this review, we focused on the local and temporal distribution of $\mathrm{Q}$ fever, highlighting the risk factors involved in each episode, and the variable differences between each one, also studying its expansion on the development criterion or not of the affected countries. Additionally, knowing more the microbial aspect of Coxiella burnetii, may give us answers that will illuminate the knowledge and research paths on Q Fever.

$Q$ fever outbreaks, in time and place.

History and first description of Coxiella burnetii

Firstly, in the 1930s, the causative agent of $Q$ fever was described simultaneously in two near concurrent incidences in two different continents; Queensland, Australia and in Montana, USA [1]. After the august 1935 incident of undiagnosed febrile illness among abattoir workers in Brisbane, Queensland; Edward Derrick was assigned to investigate the cause of this epidemic [1-3], which led him to name the disease " $Q$ " fever in reference to the first letter of English word "Query" meaning "Question" until fuller knowledge should allow a better name [4]. Consequently, Derrick failed to identify the infectious agent of this disease, but he was able to transmit the fever to guinea pigs in blood and urine from infected patients. In the meantime, he concluded wrongly that the etiologic agent was a "virus". However, Burnet and Freeman also indicated the Rickettsia-like properties in smears from the spleen of infected mice [5]. Meanwhile, on the other side of the pacific in Montana, USA, coincidentally to research on Rocky Mountain Spotted Fever, an unknown tick infectious agent, passing through filters, infecting the guinea pigs, Gram-negative, and produced unexpected clinical signs, it was named The Nine Mile Agent. Rolla Dyer, Being the Director of the National Institutes of Health, USA, after a laboratoryacquired infection by the new agent, this step led him to report a breakthrough and confirmed that the Australian and American groups were investigating the same organism. It was proposed to rename the organism; Coxiella burnetii to credit both groups for their pioneering research into this newly identified infectious agent [6-8].

\section{Worldwide Q fever outbreaks mapping}

Coxiella burnetii has been flagged where it has been searched for. Due to the epidemiological surveys in most developed countries, clear pictures about exposure factors, hosts-reservoirs life cycle are amply described, hence its incidence is generally quite low. In developing countries, information on endemicity is generally scare and limited to seroprevalence studies in exposed populations or case reports. This presumably reflects misdiagnosis, rather than lower incidence [9]. Most reports of Q fever outbreaks are from rural areas and rare associated directly or indirectly with farms or farm animals $[10,11]$. Nevertheless, urban outbreaks have been described after exposure to slaughterhouses [12,13], animal research laboratories, parturient cats, contaminated straw, and following wind-borne spread of Coxiella burnetii from farmlands [14]. In some Urban outbreaks, the source of infection was never determined [15].

\section{$Q$ fever in developed countries}

\section{Australia}

After the first descriptive investigations of the causative agent of $\mathrm{Q}$ fever, Australia has been known as the cradle of Coxiella burnetii. In 1930s, following the acute onset of a distinct clinical entity among the abattoir employees and dairy farmers in Brisbane, tens of cases of a Query fever have been reported. Subsequently, Derrick's investigations showed that it was the first $Q$ fever outbreak ever registered in history, where 09 cases have been confirmed by guinea pigs transmission. Thereby, an occupational aspect has been attributed to this first outbreak. Since, Australia has experienced several outbreaks and episodes of sporadic cases of $\mathrm{Q}$ fever, consequently, it is considered one of the countries with highest rates of the $\mathrm{Q}$ fever in the world; 1.9 cases/100 000 populations, which is the mean annual national rate between 2004-2013. In addition, more than 50 cases/100 000 populations, have been reported in South-West Queensland and north-West New South Wales [16]. In 2015, in New South Wales, an atypical outbreak of Q fever affecting low-risk residents of a remote rural town, presenting different historic profile of $\mathrm{Q}$ fever notifications from this region, where the hypotheses were based around the inhalation of aerosols or dust contaminated, or also transmission via ticks due to the increased activity of Kangaroo in and around town [18]. In other side, Victoria's 10 year mean annual rate is 0.5 cases/100 000 populations [16]. Nonetheless, a current review published in 2018, included 10 years' retrospective study (1994-2003) of human acute $Q$ fever in Victoria, confirmed a total of 659 cases of acute $Q$ fever, allowing decreased rate for $4.2 \%$ per annum; among others, abattoir workers and related occupations rate decreased to $10.9 \%$ per annum, whereas those among dairy farmer's rate to $14.9 \%$ per annum, this improvement may result from the success of the vaccination's pro- 
gram of high-risk works in Australia [16]. A recent Q fever outbreak (2012-2014), was linked to an intensive goat and sheep dairy farm in Victoria, where a seroprevalence of $15 \%$ of non-pregnant milking goats were reported, confirming an active infection for different animal species; consequently, seventeen employees and one family member were confirmed with $Q$ fever over a 28-month period. In this outbreak, the genotyping of the causative Coxiella burnetii was identical in both human and goat, that clearly defines the source of this outbreak [17].

\section{United States}

In the 1930's, United states was among the first countries which identified the causative agent of $\mathrm{Q}$ fever disease Coxiella burnetii; by studying a pathogen that can be transmitted via ticks in Rocky Mountain Spotted Fever. In March 1946, an explosive outbreak of illnesses happened among Stock Handlers and Slaughterhouse Workers in Amarillo, Texas. In order to better investigate the serological profile of Q fever disease; Derrick and Cox considered wise to use a serological test which being of great assistance in retrospective diagnosis. The observations showed that the WeilFelix test gives negative evidence in $\mathrm{Q}$ fever, however the Complement Fixation provides an adequate serological profile. A total of 55 sera were collected from patients infected in this outbreak, and tested by the complement fixation method, it appeared that 49 were $\mathrm{Q}$ fever positive, and the titers were low as a rule during the first week of illness. Subsequently the titers generally reached and maintained high levels at least for a few weeks [19]. To better characterize Q fever epidemiology in the United States, an extensive review was realized between 1946 and 1986. Published reports of national disease surveillance, individual cases, outbreak investigations, and serologic surveys were reviewed, where a variety of diagnostic tests were used to detect antibodies to Coxiella burnetii, which varied in their diagnostic sensitivity and specificity, and their criteria for defining a positive result. In national surveillance reports from 1948-1978, a total of 1168 human cases were reported, with a mean of 38.9 cases/year, the cases were reported from almost every state but in California the cases were highest. Otherwise, the human cases mean decreased to 28.5 cases/year between 1978-1986. Among human cases, livestock handlers had a significantly higher prevalence of antibodies to Coxiella burnetii than did persons with no known risk. In this review, animal studies showed that goats had a significantly higher average seroprevalence $(41.6 \%)$ than sheep $(16.5 \%)$ or cattle (3.4\%). Evidence of antibody to Coxiella burnetii was reported also among various wild-animal species, including coyotes, foxes, rodents, skunks, raccoons, rabbits, deer, and birds [20]. In 2006, Q fever endocarditis based on an extremely high antibody titers against Coxiella burnetii phase I antigen despite treatment by Doxycycline with recurrent fever for 14 months, was followed for 10 years with 31 years old farmer from West Virginia, having a history of congenital heart dis- ease, including dextrocardia, a double-outlet right ventricle, a ventricular septal defect and sever pulmonary stenosis. This case represents the longest follow-up period for a patient with chronic $Q$ fever in the United States [21]. In 2011, a multistate Human Q fever outbreak was reported. The episode began in April 2011, when an abortion storm took place among goat-farm in Washington, where 14 aborted cases $(28 \%)$ ) were described by the farm's owners, and Coxiella burnetii positive goat placental specimens were collected. One month later, a patient with flu-like symptoms tested positive for $\mathrm{Q}$ fever in Washington state and described similar symptoms in other household members. Days after, multiple cases of $Q$ fever were reported in Montana. Twenty-one (21) human cases registered in both Washington and Montana states, were linked to visitors exposed to direct contact with goat new born originated from a single farm in Grant County, Washington where the abortion storm occurred one month earlier. In addition, Interviews with the WA Farm A owners, and review of their sales records, led to an expanded list of epidemiologically linked farms. Goats sold by from WA Farm A were traced to 20 other farms in 14 counties across three states (Washington, Montana, and Oregon). The owners of 17 total farms (13 in Washington, including WA Farm A; three in Montana; one in Oregon) were contacted and agreed to participate in the outbreak investigation [22]. In October 2015, a rare Q fever outbreak hit the United States, when five American medical tourists came down with an unusual illness after travelling to Germany for a controversial treatment involving injections with sheep cells which aims to improve their health and vitality. Coxiella burnetii was identified as the causative agent of this outbreak. The treatment is not permitted in the United States. The five New York residents received the "live cell therapy" in May 2015. About a week later, they developed fever, fatigue and other symptoms in favour of Coxiella burnetii infection. Three of them were recovered but two still experiencing symptoms more than 9 months later [23]. Recently, Pettey., et al. reported A case of $\mathrm{Q}$ fever after liver transplantation, this case highlights the need to include $Q$ fever in the differential diagnosis for fever of unknown origin in solid organ transplant hosts [205].

\section{Netherlands}

Since 2007, one of the largest reported outbreak of Q fever in humans ever reported in the literatures, occurred in the Netherlands, involving 4026 cases, at least 14 of these patients, nearly all of them with severe underlying conditions, have died. Epidemiological investigations identified small ruminants as source, especially goat [24-26]. The question which is getting a lot of attention and it's still hanging; in this developed countries, how such a historical epidemic can occur? And that so many cases are reported? In order to answer to this question, we have to clarify that three factorial axes could be incriminated: First, the increasing number of goats in highly populated areas noting the close distance between livestock farms and dwelling place; more than 140000 received 
goats had been enrolled from 2000 to 2009, therefore the goat farms increased from 33 to 58 farms which greatly accentuated the risk of goat-human infection. Second, environmental factors could be charged too, in 2007 the Netherlands has known a large dry period without rain, this climate could promote the transmission of Coxiella burnetii from infected farms [27]. Third, possible introduction of a more virulent strain of Coxiella burnetii, in this manner, the central veterinary institute has reported that one Multilocus Variable-number tandem-repeat Analysis (MLVA) type prevails on many dairy goat farms in the southern part of the Netherlands $[26,27]$. Moreover, the lack of contact between the veterinary sector and the human health sector, it has had an impact on the communication of information about the $Q$ fever outbreak in animal environment, which has not been communicated in time. In December 2009, it was decided to start culling more than 50000 pregnant goats on infected farms, this decision has had an important impact, but unfortunately these interventions were issued too late [28].

\section{France}

In France, from 1985 to 2009, 3727 patients had acute Q fever (one third female patients), where the yearly distribution of acute $\mathrm{Q}$ fever showed a continuous increase. $\mathrm{Q}$ fever was diagnosed more often in southern France, where the French National Reference Center (NRC) is situated (Marseille). This increase incidence suggests several interpretations, one of them, could be the improved diagnostic capability caused by development and availability of commercial diagnostic test [29]. However, in France, some investigations on the $\mathrm{Q}$ fever outbreaks have focused on another risk factor in Coxiella burnetii transmission; including the influence of weather conditions on the spread and escalation of $Q$ fever cases, namely wind frequencies according to the seasons and its changes. The Mistral is a corridor wind, from northwest to north, which concerns the northern part of the western Mediterranean basin. It can blow at more than $100 \mathrm{~km} / \mathrm{h}$ in the plain, especially in the lower Rhône valley.

Studies have been carried out to investigate the link between the mistral wind and outbreaks of $\mathrm{Q}$ fever in the Bouches-duRhones region, particularly in Marseille, Aix en Provence and the Martigues region. Between 1990 and 2003, two major studies have been conducted. The first was realized from 1990 to 1995 in Martigues regions, small town in the western Marseille, it extends along the banks of the Etang de Berre and the Caronte Canal. This small town, apparently has more cases of $Q$ fever than the surrounding towns, subsequently it was judicious to investigate the Q fever epidemiologic situation of Martigues. Because infectious particles containing Coxiella burnetii can easily be transported by the wind, and the fact that a large number of sheep are located windward of the study area, we wanted to determine whether wind direction and strength, as well as sheep breeding, could be significantly associated with the seasonal distribution of cases that occur in the study area. In the study's period, 289 patients had been admitted with an active $Q$ fever, with a high incidence from the Etang de Berre region with 35.4/100 000 inhabitants, where the Mistral ( $>8 \mathrm{~m} / \mathrm{s})$, which blows on the local steppe where more than 70000 sheep are breed in open fields. The results showed that the seasonal distribution of the cases with that of the Mistral in the areas study, shows a clear correlation between this wind and the number of $\mathrm{Q}$ fever cases, Consequently, there is a highly endemic area close to Marseille, which constitutes a significant public health threat to the population [30]. In the second study, in the Marseille region, authors hypothesized that the norther wind (The Mistral) that blows over a slaughterhouse which is used 1 day each year by Muslim population of Marseille for the traditional sheep feat "Aid El-kebir", it also blows towards two shelters which are 2 till 6 Kilometres away from this slaughterhouse; thus the Mistral may involve in spreading of Coxiella burnetii. From 1999 to 2003, a total of 668 homeless were recruited, especially during the year period when the slaughterhouse was used in Sheep Feast, in 04 years, the strength of the Mistral measured as a mean of the daily recorded was $30.37 \mathrm{Km} / \mathrm{h}$ (1999: 12 days, $36.8 \mathrm{Km} / \mathrm{h}$; 2000: 2 days, 28.4 $\mathrm{Km} / \mathrm{h}$; 2001: 1 day, $26.2 \mathrm{Km} / \mathrm{h} ; 2002: 6$ days, $30.1 \mathrm{Km} / \mathrm{h})$. Results showed that Coxiella burnetii IgG phase II antibodies were found in 27 of $668(4.04 \%)$ in the two shelters. To conclude, homeless were likely exposed to Coxiella burnetii in shelters during the month that followed the "Aid El-Kebir", where the Mistral wind playing a critical role in this outbreak [13]. In addition, another study suggested the aerosols contamination by Coxiella burnetii, between 01 April and 26 June 1996, an outbreak of Q fever with 29 cases of acute Q fever, was observed among the inhabitants of Briançon, a town located in the French region of the Hautes Alpes, where goats, cattle, and sheep are bred in this area, but the main farms are located far from the town itself. Located in the town of Briançon, a slaughterhouse whose major activity of slaughtering was usually conducted between February and April, especially in the period before Easter (lamb meat is traditionally eaten during the Catholic Easter meal), this slaughterhouse was incriminated as source of spreading of Coxiella burnetii. The wind spreading was suspected in this outbreak, but they were unable to formally demonstrate the role of the heliport. One question remains: Why did this outbreak occur during the year 1996? This epidemic probably followed a Q fever outbreak among the sheep, as has been described by Dupuis., et al. in a Swiss Alpine valley [32]. A longitudinal follow-up study of a naturally infected sheep flock was performed by Joulie., et al. in 2017 , in order to investigate relationships between seropositivity and bacterial shedding in the vaginal mucus, describe the kinetics of antibodies, including responses to vaccination, monitor maternal antibodies in ewe lambs, and compare serological results in 
milk and serum samples. They reported that some dairy females did not seroconvert although they shed Coxiella burnetii in their vaginal mucus or despite vaccination. Overall, antibody levels in adult females were found to remain stable over time, with exceptions during the mating and lambing periods. Maternal antibodies decreased during the first month after birth. Interestingly, antibody levels in milk were correlated with those in serum [204].

\section{United Kingdom}

According to the $\mathrm{Q}$ fever's historic in the United Kingdom, we can deduce that most cases of $Q$ fever in UK are sporadic. $Q$ fever cases number had a tendency to increase considerably from 1970 till 1995, reaching a stable incidence ranging from 0.15 to 0.35 cases $/ 100000$ inhabitants per year [33]. For the same period, outbreaks reported in the literature, in different parts of UK, showed the professional aspect of Coxiella burnetii contamination, within laboratories staff, postal workers, and experimental research staff [33]. In addition, we can halt on the largest outbreak in UK occurred in Solihull 1989, in which the cases were associated with windborne spread from farmland to an urban area [34,35]. South Wales in September 2002, during the renovation of cardboard manufacturing plant, likely the potential contamination by Coxiella burnetii of the straw board in walls and ceilings disturbed by this workshop, was associated to a Q fever outbreak, where 95 employees and subcontractors were serologically positive for an acute infection [36]. Furthermore, in summer 2006, a widespread outbreak recorded in Scotland, occurred at a rural co-located slaughterhouse and cutting plant. The outbreak's investigations reinforced the rejection of the null hypothesis of no association between inhalation of aerosols contaminated with fomites from the sheep lairage and testing positive for $\mathrm{Q}$ fever. The onset went off when the Scottish Public Health Department received notification of respiratory and gastrointestinal symptoms in employees of the plant, at that time, the plant was dealing with the slaughter, boning and dispatching of approximately 1650 cattle and 5000 to 10000 sheep per week. Consequently, 110 confirmed from 179 suspected cases were reported [37].

"We believed that sharing and applying different techniques and information between different fields of research is of paramount importance for successful outbreak investigation", that was the slogan of a multi-sectoral team that contributed with close collaboration and information exchange, within veterinary, human health, and meteorological agencies and local authorities on outbreak investigations which occurred in Cheltenham. In June 2007, The Gloucestershire Health Protection Team, reported 30 Q fever confirmed cases living in the town of Cheltenham where no cases had been reported in this area in the previous three years. Telephone survey was conducted to identify risk practices at lo- cal farms. In the meantime, and for the first often, the Numerical Atmospheric-dispersing Modelling Environment "NAME" was used in order to identify whether air from the identified sheep in nearby; the modelling showed that air from all the three farms was carried over Cheltenham in the estimated risk period. According to the previous outbreaks, $2 \%$ to $5 \%$ of those infected may be hospitalised; extrapolating from the cases we identified retrospectively through 15 hospital admission, suggests that possibly up to 500 people may have been infected (with the asymptomatic Q fever form) [38].

\section{NAME: Numerical Atmospheric-dispersion Modelling Environ-} ment

The areas of highest dosage (pink, orange and yellow) covers Cheltenham town centre. A black diamond marks the location of the farm. Red dots mark the addresses of cases resident in Cheltenham. A black line illustrates the outer limit of the built up areas in Cheltenham. The filled black circle marks the town centre which
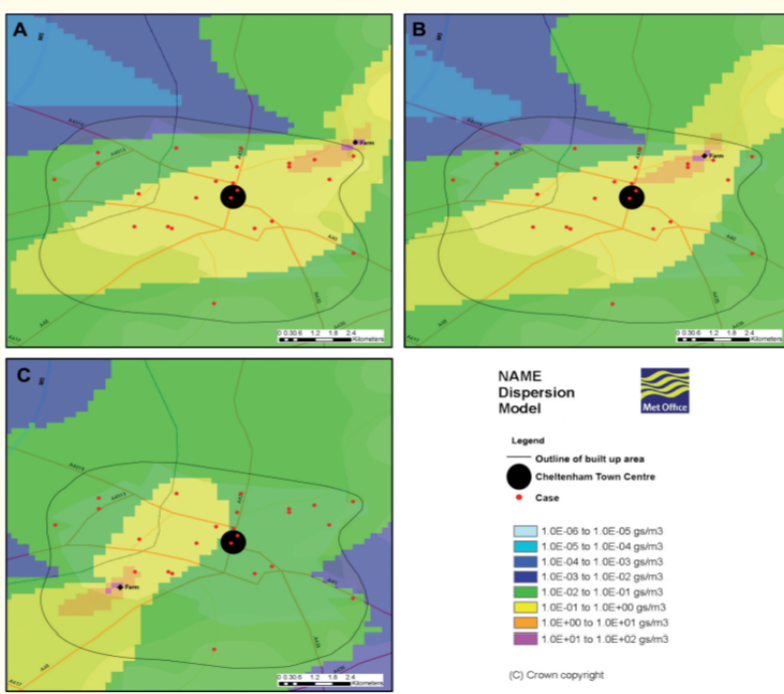

Figure 1: NAME air dosage maps obtained by modelling a continuous release from the high risk farms (A, B, and C) for the time period 23 April-7 May 2007. (Reprinted from Wallensten et al, 2010)

\section{Q fever in other developed countries}

In Switzerland, a central Europe country, Q fever registers a low endemicity, with an incidence of 0.15 cases/100 000 inhabitants per year, corresponding to 10-12 cases per year. Since 1999, reports of human cases to public health authorities were no longer mandatory, consequently its epidemiology is now largely unknown. In addition to the large Swiss outbreak of Q fever occurred in 1983, 
with 415 human cases were reported, another outbreak had occurred in 2012, in Terrace vineyards of Lavaux, where 10 acute $Q$ fever human cases were diagnosed, and the investigations showed that the epidemiological source was the sheep flocks which gave $43 \%$ of seropositivity in this region [39]. In the same continent, in 2016 an unusual outbreak of Q fever took place in manufacturers of hoists and chains in Spain, in this epidemic episode, no apparent occupational-associated risk was noted, and 08 employees were detected with an acute $\mathrm{Q}$ fever. The widespread distribution of Coxiella burnetii DNA in dust samples collected from the plant facilities, suggests that the infection had occurred inside this factory, and the most probable vehicle for the bacteria entering the factory was the worker's boots which were worn inside the infected goat farms and also in the factory [40]. The Canary Islands (Spain) are considered an endemic territory, with a high prevalence in both humans and livestock. A study conducted by Bolanos-Rivero., et al. in 2017, aiming to Detect Coxiella burnetii DNA in peridomestic and wild animals and Ticks in Canary Island. They found eight rodents $(8 \%)$ and two rabbits $(1.5 \%)$ were found to be positive, with the spleen being the most affected organ, and also $6.1 \%$ of the processed ticks distributed between those removed from livestock (11.3\%), domestic dogs (6.9\%), and from wild animals (6\%) [203].

Slovakia, in 1952, the first outbreak of Q fever in was occurred among agricultural workers, the source of infection was a sheep flock imported from Romania. More recently, in September 1992, the largest outbreak of human $Q$ fever in Slovakia began as a result of imports of 1181 goats from Bulgaria. Within the next two months, several abortions occured which resulted in two outbreaks. During the first one, 11 humans who were in direct contact with animals were infected [200]. The second epidemic, however, involved as many as 113 human cases. Epidemiological investigations revealed that the source of infection was a contaminated aerosol in a local pub that arose from the clothing of farm workers who witnessed the abortion of one of the goat shortly before [201].

In Turkey, as an Asian country, Q fever has not shaken the Turkish people as a new infection; in 1953, Payzin described it as follows: "The occurrence of the infection among human beings animals throughout Turkey suggests that is not a New disease in this country, and the disease has been known to the Turkish people as an animal infection, under the name 'ESKI HASTALIK' which means 'Old disease' [41]. Thereby, the first outbreak of the $Q$ fever was reported in 1948in Akasaray province, where 21 human cases were diagnosed. Recently in 2000s, precisely in 2002, an outbreak of Q fever was reported near the Black Sea region in Northern Turkey, with 46 human cases, and most of them from Tokat province [42]. In Turkey, as in other parts of the world, the results of seropositivity significantly differ in terms of the regions and study groups.
In 2008, Kilic found a seroprevalence of $32.3 \%$ in people residing in Urban Turkish area [43]. A series of Turkish studies conducted between 2006 and 2011 with high risk group, showed that a seroprevalence of $65.9 \%$ in slaughterhouse workers, $42.9 \%$ in Butchers, $32.8 \%$ in farmer, $30.6 \%$ in veterinarians, $32 \%$ in veterinary technicians, $28.5 \%$ in animal lovers [43-45]. Despite these evidences, the number of studies conducted to investigate the seroprevalence of Coxiella burnetii in Turkey over the last few years is very limited. In Eastern turkey, Erzincam Province, 2017, an overall seroprevalence of Coxiella burnetii was found to be $8.7 \%$ in rural and nonrural residents, with significant risk factors including raising cattle and exposure to infected animals or their birth products [46].

In China, the disease was initially reported in 1950 and in between 1989-2013, there have been 29 reports on Q fever in this country. Studies' results showed that the overall prevalence of Coxiella burnetii infections in the reports is $10 \%$ in humans, $15 \%$ in cattle and $12 \%$ in goats. Cattle and goats had the highest seroprevalence of all the domestic animals studied and a wide variety of ticks were found to be infected. Mice were also commonly infected and had high copy numbers of Coxiella burnetii DNA, suggesting they might be important in the epidemiology of $Q$ fever in China [48].

In December 2016, The Europrean Surveillance Sysytem "TESSy" reported that 27 EU/EEA countries provided information on Q fever in humans, reporting a total of 851 cases, 824 of which were confirmed $(96.2 \%)$. In the same report, six countries reported zero cases in 2015 ((Estonia, Iceland, Lithuania, Malta, Poland and Slovakia). Paradoxically, in Poland, a study published in 2015 was carried out in order to have a prevalence of Coxiella burnetii in humans occupationally exposed to animals, where 46 human cases were confirmed serologically (IFA), within 10 samples presented the presence of specific sequences of Coxiella burnetii DNA BY using the real-time PCR. These results confirmed the presence of $Q$ fever in Poland, thing has been denied by TESSy's report $[47,49]$. The question stills hanging, is the TESSy reports are based only on the countries reports? Do countries take into account the results of research that has been carried out? It's just to clarify the reliability of reports given by the TESSy. According to the TESSy 2016 report, the number of cases reported in 2015 is higher than during the years 2011 to 2014. The number of cases dropped in 2012 to increase again in the following years. Between 2012 and 2015, the number of confirmed cases increased by $56 \%$. In 2015 , the notification rate was 0.19 cases per 100000 populations, which is similar than in 2011 but higher than in 2012, 2013 and 2014. From 2011 to 2015 , the notification rate was varying between 0.12 and 0.19 cases per 100000 populations. On the following table (Table 1), numbers and rates of confirmed $Q$ fever cases in some European countries between 2011 and 2015 [49]. 


\begin{tabular}{|l|c|c|c|c|c|c|c|c|c|c|}
\hline \multirow{3}{*}{ Country } & \multicolumn{2}{|c|}{2011} & \multicolumn{2}{c|}{$\mathbf{2 0 1 2}$} & \multicolumn{2}{c|}{2013} & \multicolumn{2}{c|}{2014} & 2015 \\
\cline { 2 - 13 } & Confirmed cases & Confirmed cases & \multicolumn{2}{c|}{ Confirmed cases } & \multicolumn{2}{c|}{ Confirmed cases } & \multicolumn{2}{c|}{ Confirmed cases } \\
\cline { 2 - 13 } & Number & Rate & Number & Rate & Number & Rate & Number & Rate & Number & Rate \\
\hline Belgium & 6 & 0.1 & 18 & 0.2 & 5 & 0.0 & 4 & 0.0 & 8 & 0.1 \\
\hline Estonia & 0 & 0.0 & 0 & 0.0 & 0 & 0.0 & 0 & 0.0 & 0 & 0.0 \\
\hline France & 228 & 0.4 & 5 & 0.0 & 158 & 0.2 & 209 & 0.3 & 250 & 0.4 \\
\hline Germany & 285 & 0.4 & 198 & 0.2 & 114 & 0.1 & 238 & 0.3 & 311 & 0.4 \\
\hline Netherlands & 80 & 0.5 & 63 & 0.4 & 20 & 0.1 & 26 & 0.2 & 20 & 0.1 \\
\hline Poland & 0 & 0.0 & 0 & 0.0 & 0 & 0.0 & 1 & 0.0 & 0 & 0.0 \\
\hline Spain & 33 & - & 58 & - & 75 & - & 77 & - & 97 & - \\
\hline United Kingdom & 43 & 0.1 & 12 & 0.0 & 46 & 0.1 & 60 & 0.1 & 21 & 0.0 \\
\hline
\end{tabular}

Table 1: Number and rate per 100000 of confirmed Q fever cases by country and year, EU/EEA, 2011-2015

(adapted from The Europrean Surveillance Sysytem, 2016).

$Q$ fever in developing countries

In most developing countries, $\mathrm{Q}$ fever diagnostic tools are not well available, consequently its overall impact on public health was widely underestimated. Otherwise, we haven't a clear epidemiological profile of $Q$ fever in these countries. As a result, registered outbreaks and their studies are quite rare, except recent studies occurred in some countries which aimed to identify reservoirs and contamination sources of Coxiella burnetii to humans.

\section{First Q fever clinical cases and outbreaks in Africa}

Since 1947, the Q fever has caused a major epidemic in Africa countries. In Southern Morocco, a focus of Q fever was discovered by Blanc in 1947 [50], then the first isolation of Coxiella burnetii (old Rickettsia burnetii) was done in Congo from three human subjects, where the organism was also isolated from cows' and goats' milk, dog and cattle ticks, and human body lice [52].

In 1950, the Third World Health Assembly (WHA), aware of the potential danger of $\mathrm{Q}$ fever to public health and of the large gaps in the existing knowledge of the disease, passed a resolution calling for a preliminary study of its prevalence throughout the world. A program of epidemiological research and surveys was accordingly encouraged by the WHA in 33 countries. In 1951, in three Northern African countries, Algeria, Morocco and Libya. Throughout Morocco, Q fever outbreaks were assigned in six towns with $38 \%$ human infection and $55 \%$ goats, $45 \%$ cows and $38 \%$ sheep. In addition, 02 human clinical cases and 22 human cases among men of the United State Air Force (USAF) stationed in Tripoli, were reported in Algeria and Libya respectively [52]. In 1952, Halawani and colobarotors, reported 11 positive human cases from 77 in Egypt. Moreover, the WHO survey revealed 27 positive goat's sera from 230, 9 positive goats and sheep from a total of 929 in Tunisia [51]. In 1953, Giroud., et al. state in the slaughter-houses in Douala,
Cameroons, 16 positive sera from 113 healthy workers [53]. More recently in 1955, Kaplan reported human cases of Q fever in nine African countries, from Morocco to South Africa, suggesting that the infection was widespread in that continent [52]. In 1957 and 1958, others outbreaks have been reported in Batna and in Tlemcen in Algeria [54].

\section{Recent $Q$ fever in Africa}

At the twilight of the last century and at the early of the $21^{\text {st }}$ one, studies on the causative agent of $Q$ fever have taken on a new dimension in African countries, where we note an increase in the results obtained following research work in the subject, as well as collaborations between the various actors in the health sector in order to detect reservoirs and sources of $\mathrm{Q}$ fever contamination, and know more about the pathogen. Coxiella burnetii infection is detected in humans and in a wide range of animal species across Africa, but seroprevalence varies widely by species and location.

In 1995, seroprevalence studies of Q fever conducted by Raoult., et al. showed the highest seropositivity rates in Mali, Burkinafaso, Nigeria and Central African Republic, which are countries with the highest density of domestic ruminants [55]. In addition, $1 \%$ of patients in Casablanca and 18\% in Fez in Morocco had reactive antibodies phase II to Coxiella burnetii [56]. In 2003, Schelling states the seroprevalence rate in human of $1 \%$ in Chad, and $80 \%$ of camels seropositive in Egypt [57]. Three years earlier, Potasman published the fact that $Q$ fever has been reported in travellers returning from a safari tour [58]. In Sousse hospital, in Tunisia, 26\% of blood donors were seropositive for acute $Q$ fever in 2008. At the same year Letaief reported 21 acute $Q$ fever cases among patients hospitalized for acute fever illness in Tunisia [59]. Simultaneously, in Ghana rural Ashanti region, $17 \%$ of two-year-olds of population study were seropositive to Coxiella burnetii [60]. In addition to be- 
ing sources for disease transmission to humans, Coxiella burnetii in animals can decrease livestock productivity which can have socioeconomic and indirect health effects on humans, especially among livestock-keeping populations in resource-limited settings [61].

In an agropastoral region of Algeria, seroprevalence rates of $15 \%$ with peaks up $30 \%$ in villages where the disease is hyperendemic, have been observed in Eastern Algeria in 2009 [54]. The causative aspect was the close contact with infected animal and their products, as consumption of unpasteurized raw milk which was incriminated in pathogen shedding in bovine milk with $22 \%$ of raw milk in Egypt in 2009 [62]. From 2010 to 2011; many studies have been conducted, where thy mentioned $4 \%$ and $32 \%$ cattle seroprevalence in Nigeria and Cameroons respectively $[63,64]$. In addition, both in Senegal and Tanzania, seroprevalence of Q fever was $24.5 \%$ and $5 \%$ of the population study correspondingly [6567], with febrile illness and sever pneumonia cases. Moreover, in most African countries, seroprevalence rates are elevated in domestic ruminants, surveys in cattle showed rates ranging from $4 \%$ in Senegal to 33\% in Nigeria and 18\% in Ghana [68]. In 2012, different countries investigated $Q$ fever animal contamination sources, mainly goat, sheep and cattle. In Egypt and Sudan, the seroprevalence in Goat was nearly similar with $24 \%$, otherwise the sheep seroprevalence was higher in Egypt with 33\%, this could be due to the intensive breeding of sheep and goats which are widespread in, even to the human close contact with these species $[69,70]$. Consequently, the Coxiella burnetii infection may spread in human, which could explain the different $Q$ fever seroprevalence rates that varying across countries. Schelling., et al. in 2012, state a seroprevalence of 16\% in Egyptian patients [71]. Moreover, in 2013 Crump., et al. conducted an investigation in cohort in Tanzania of severely ill febrile patients where they found $26.2 \%$ zoonosis, among which $30 \%$ where due to $Q$ fever infection [72]. Concurrently, in rural clinic in western Kenya, a seroprevalence survey on banked sera of febrile patients, who were diagnosed for an acute lower respiratory infection, being found to have acute $\mathrm{Q}$ fever with 3\% from a total of $30.9 \%$ as a global rate, reported Knobel., et al [73]. In rural regions of most of these countries, human households are in close vicinity to domestic ruminants, making transmission easier than it is elsewhere, as a result, Ratmanov detected Coxiella burnetii DNA in $2 \%$ to $22 \%$ of household samples in rural Senegal [74].

Aiming to study Coxiella burnetii in febrile patients in rural and urban Africa, in 2014 Angelakis., et al, worked for blood samples from febrile and non-febrile patients from six African countries and from France were investigated retrospectively for $Q$ fever infection by molecular assays targeting the IS1111 and IS30A spacers. Results showed that no cases were found in Morocco, Tunisia and Mali with 00/48,00/84 and 00/400 samples respectively. However, 6 positive q PCR for both IS1111 and IS30A spacers were found in Senegal from a total of 511 blood samples. In Oran, Algeria, they found one patient infected with Coxiella burnetii who presented asthenia, respiratory symptoms and suffered from a persistent fever and myalgia for 6 days. The installation of point-of-care laboratories in rural Africa can be a very effective tool for studying the epidemiology of many infectious diseases [65]. Vanderburg published in 2014 a Systematic Review dealing the epidemiology of Coxiella burnetii Infection in Africa. In a part, he described a human cohorts comprising individuals with infective endocarditis in Sousse and Sfax, Tunisia, as well as Algiers, Algeria, have demonstrated Coxiella burnetii as the causative pathogen in 1-3\% of cases [61]. He concluded that Coxiella burnetii has been implicated as a cause of livestock abortion and could be responsible for substantial economic burdens, but more rigorous studies are required to determine this and other sequelae of disease in animals. Secondly he judges that risk factors for human exposure to $Q$ fever are poorly understood, but a more detailed understanding of how human exposure in different communities is linked with animal infection patterns and animal husbandry practices is clearly needed [61]. As in Nigeria, Coxiella burnetii has been detected in up to $60 \%$ of cattle milk samples, which is considered as source of human contamination [61].

In Algeria, Khaled in 2016, conducted a study in order to identify the positive sources of $Q$ fever in Algeria; where he found a seroprevalence of $14.1 \%$ among small ruminant's flocks, and he determined the shedder flocks of Coxiella burnetii via the vaginal swab with 21.3\% q PCR positive [76]. Whereas, Bessas and Aouadi in the same year, reported the presence of Coxiella burnetii by $\mathrm{q}$ PCR in spleen dog $(0.80 \%)$ and blood/ticks of small ruminant $(4.73 \%)$ respectively $[75,77]$. These results could lead to the various sources of Coxiella burnetii contamination in Algeria. More recently, in 2017, Benaissa studied the causative agent of Q fever in the dromedary camel (Camelus dromedarius) population in Algeria, where he found that antibodies to Coxiella burnetii were found in $71.2 \%$ of all camels investigated and the true prevalence was calculated as $71.1 \%$ [Dromedary Algeria], these result prove that even in southern Algeria where the highest temperature are registered in Algeria (up $58^{\circ} \mathrm{C}$ ) Coxiella burnetii could escape and infect one of the highest immune system in animal world, thus the pathogen's high resistance to high temperatures in the outside environment could be demonstrated [78]. Abushahba., et al. in 2017, between August 2016 and January 2017, in El Minya -Egypt, calculated a seroprevalence of Coxiella burnetii IgG antibodies, with $25.68 \%, 28.20 \%$, and $25.71 \%$ in sheep, goat, and humans respectively, which clearly points out that Q Fever may be emerging in this area [210]. A few Coxiella burnetii genotypes (including genotypes 2,6,16,19,30,35,36 and 52) have been characterized in Africa, mainly in ticks; only genotypes 19 and 35 have been detected so far in human $[66,79]$. 


\section{Q Fever in others developing countries}

$\mathrm{Q}$ fever presence in the Middle Easter areas is being reported from Syria [80], in 2000, when Bottieau reported that a Belgian patient developed Q fever after a journey in Syria, thus Coxiella burnetii infection was diagnosed because of the presence of granulomas with a central vacuole in a bone marrow biopsy. Furthermore, Faix in 2005, described Q fever outbreak occurred in 22 (58\%) of 38 US-Marines deployed to Iraq, all patients presented Fever, while respiratory symptoms were found in $76 \%$, and gastrointestinal symptoms in 53\% were, dust and exposure to animals and ticks were the main risk factors incriminated [82].

In Iran, the first clinical case of acute $Q$ fever in human was reported in 1952 [83]. Then positive cases of infection with Coxiella burnetii in cattle, sheep, and goats had been reported as $7 \%$, $3.2 \%$ and $1.7 \%$ respectively in 1976 ; after this year, the disease was forgotten in Iran and no human cases were reported. In 2011, a cross-sectional study was conducted in different regions of the Sistan va Baluchestan province, in Iran, a total of 190 sera were collected from butchers and slaughterhouse workers; phase I and II of Q fever were found $18.1 \%$ and $14.4 \%$, respectively; Additionally, a significant relationship was found between seropositivity of Q fever and camel slaughtering [81]. Kayedi in 2014, found 45 sheep among 330 ones (13.64\%) tested positive for IgG for Q fever and 23 animals were border-line (6.97\%) [84]. Moreover, in 2017, Mobarez states the overall seroprevalence of IgG phase I and phase II antibodies of Q fever in human between $2005-2016$ was $19.8 \%$ and $32.86 \%$ respectively [85].

In Lebanon, information about the presence of Coxiella burnetii infection is scanty and only related to a survey performed in the last century when Garadebian recorded Coxiella burnetii between both sick and healthy people in 1956 [86]. Last year, in 2018, for the first time in Lebanon, Dabaja studied the human seroprevalence of Q fever, where 421 human sera from 05 different Lebanese provinces, the sera were screening for IgG phase II antibodies against Coxiella burnetii Enzyme Linked Immunosorbent Assay (ELISA) Kit and IFA. Results showed that $38.70 \%$ were estimated positive samples by ELISA, and $37 \%$ by IFA test. This results were different across the 05 Lebanese province, this may be due to the presence of high density of livestock production and of major agricultural areas in Akkar and Bekaa provinces [87]. In North-western Palestine, the average annual incidence of $Q$ fever between 1998-2004, was 0.6 cases $/ 100000$ cases (20 to 70 cases per year) [88]. In this country a few outbreaks were reported, with the majority occurring in rural or adjacent areas following outbreaks of $Q$ fever in livestock, and all were relatively limited in scale. In June 2005, An unusual outbreak $Q$ fever its magnitude and place of occurrence in boarding high School in North-western Palestine was reported by Amitai, this outbreak has caused the infection of 103 students and 05 employees of the High School.
In India, the data in most of the published reports on the prevalence of Coxiella burnetii infection in humans and animals are based on results from sero-surveys employing capillary agglutination and complement fixation tests, aside from those in the few reports on the isolation of these agent. In 2008, Vaidya conducted a comparison of different diagnostic tool for $\mathrm{Q}$ fever disease in humans with spontaneous abortions. He worked for a total of 368 samples (placental bits, vaginal swabs, sera...) collected from 74 women with spontaneous abortions, using the q PCR targeting IS1111, and IFA test, results were for $25.68 \%$ IFA positive, and for $21.62 \%$. These results testify that Coxiella burnetii may be incriminated in spontaneous abortions in women [89].

In the Latin America, thorough examination of the literature in the 04 languages (English, French, Spanish, and Portuguese) testify that studies' results of $\mathrm{Q}$ fever disease are frightening although $\mathrm{Q}$ fever is present worldwide [90]. According to the available literature, 07 (Belize, Costa Rica, Guatemala, Guyana, Honduras, Paraguay, Suriname) Latin America countries have never reported any cases of $\mathrm{Q}$ fever throughout all the past century till nowadays [90]. Otherwise, in Colombia, Mexico, and Brazil, studies' results showed several seroprevalence studies in exposed populations, where some of ones are based on the febrile and the respiratory aspect of $\mathrm{Q}$ fever disease. In addition, there are no publications on $\mathrm{Q}$ fever in the Amazon region, except in and Ecuador French Guiana. In this later, which is a French oversea territory located on the Northeastern coast of South America, about $90 \%$ its $84000 \mathrm{Km}^{2}$ surface is covered by the Amazonian rainforest. Coxiella burnetii was first described in 1955 in French Guiana, but the real interest arose throughout the years. Studies found an annual incidence of 37 cases/100 000 persons between 1996-2000, up to 150 cases/100 000 persons in 2005 [91], and 17.5 cases/100 000 persons between 2008-2011 [92]. Moreover, groups at risk are not clearly defined. The main risk factor for Coxiella burnetii infections are working in construction/public works, living near bats, wild mammals, or the forest, levelling work and gardening [93].

After this great dive into the history of $\mathrm{Q}$ fever outbreaks around the world, in time and place, we were able to establish a map (Figure 2), on which we distributed chronologically the different $Q$ fever outbreaks mentioned above, based on the colors-years ratio, aiming to facilitate the monitoring and memorization of these episodes over time and in places.

\section{Microbiological aspect}

Bacterium

The pathogen agent of $\mathrm{Q}$ fever disease, Coxiella burnetii, is belonging to the gender of Coxiella, which is placed in the domain of Bacteria, Phylum of Proteobacteria, Class of Gammaproteobacteria, Order of Legionellae, family of Coxiellaceae [94]. Coxiella burnetii 


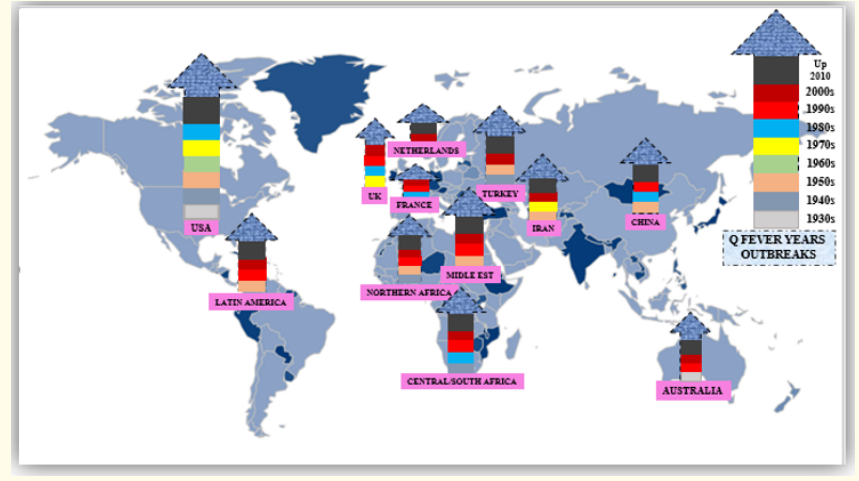

Figure 2: Q Fever outbreaks across the world, in time and place (personal synthesis).

has a cell wall similar to that of Gram-negative bacteria. However, this small coccobacillus ( 0.2 to $0.4 \mu \mathrm{m}$ wide and 0.4 to $1 \mu \mathrm{m}$ long) is not stainable with the Gram technique. The Gimenez method is used to stain Coxiella burnetii isolated in culture or directly in clinical samples [95]. The estimated doubling time of the bacterium is between 20 and $45 \mathrm{~h}$ in in vitro cell culture [96]. It is an intracellular pathogen, replicating in eukaryotic cells, targeting macrophages (lymphocytes, lymphatic nodes, spleen, liver, lungs....), monocytes blood circulating [97], trophoblasts [98]. Its existence in FreeLiving Amoebae was also described [99,88], thus in Murine adipocytes [100]. The bacterium actively participates in the genesis of intracellular vacuole which acquiring phagolysosome-like characteristics, such as an acidic $\mathrm{pH}$, acid hydrolysates, and cationic peptides, getting several strategies for adaptation to this exceptionally stressful environment [101]. First, Coxiella burnetii genome is still discovering and surprising. Its genes encode an important number of basic proteins that are probably involved in the buffering of the acidic environment of the phagolysosome-like vacuole. Also, four sodium-proton exchangers and transporters for osmo-protectants are found allowing this bacterium to confront osmotic and oxidative stresses [94]. Coxiella burnetii division mode is complicated and characterized by 2 morphologic forms corresponding to biphasic development cycle. The large-cell variant (LCV) of the bacterium is an exponentially replicating form, whereas the small-cell variant (SCV) is a stationary non-replicating form [102]. SCVs are small rods ( 0.2 to $0.5 \mu \mathrm{m}$ long) characterized by condensed chromatin, a thick envelope, and an unusual internal membrane system. LCVs have a larger size $(>0.5 \mu \mathrm{m})$, a dispersed chromatin, and an envelope similar to that of classical Gramnegative bacteria. SCVs are typical of the stationary phase and poorly active metabolically. They are observed after prolonged culture (21 days) in Vero cells and in axenic acidified cysteine citrate medium 2 (ACCM2) [103].
SCVs are stable in the environment and are highly resistant to osmotic, mechanical, chemical, heat, and desiccation stresses [104]. The transcriptome analysis of the SCV has revealed upregulated genes involved in the oxidative stress response, cell wall remodelling, and arginine acquisition. Also, SCVs show an unusually high number of cross-links in their peptidoglycan, which probably are involved in their exceptional environmental resistance [102].

The LCV transforms into the SCV, which is the spore-like form of Coxiella burnetii. In this form, the bacterium is highly resistant to environmental stress [105]. The resistance allows Coxiella burnetii to survive in the environment while keeping its infectivity [105]. Subsequently, they can survive for 7 to 10 months on wool at ambient temperature, for more than 1 month on fresh meat, and for more than 40 months in milk [96]. The high virulence of Coxiella burnetii, the possibility of its aerosolization, and its environmental stability and have led the U.S. Centers for Disease Control and Prevention (CDCP) to classify this bacterium as a category $\mathrm{B}$ biological threat agent. A bioterrorism attack with this pathogen, although not associated with the high death rates observed for Class A agent, could cause significant disability and possibly long-term consequences due to persistent infection in the population.

Phase's variation. Like several other Gram-negative species, Coxiella burnetii displays antigenic variation similar to smoothrough variation, which is related to changes in lipopolysaccharide (LPS) layer [106]. Highly virulent phase I, phenotypically expresses a full-length and smoothed LPS, are able to replicate in immunocompetent hosts. While phase II, less virulent, unable to replicate in immunocompetent hosts, phenotypically carries a rough LPS $[105,107,108]$. The situation is complicated further by phase I and phase II forms. Phase variants display different LPS lengths with phase I organisms producing a full-lengh LPS with 0 antigen sugars, and phase II organisms producing a truncated LPS without 0 antigen [109]. LPS is demonstrated in both the Coxiella burnetii LCV and SCV, although presence of LPS is mainly associated with the SCV [110]. When mixed population of Coxiella burnetii's phase I and phase II, is injected to an immunocompetent host (animal model), phase II bacteria, unable to infect cells, are eliminated, this led getting a homogeneous population of phase I bacteria [111]. During serial passage in cell culture, phase I Coxiella burnetii can convert into phase II [112]. Both LPS phenotypes can be distinguished via phase-specific antibodies. Phase I antibodies are directed against the full-length LPS of phase I, whereas phase II antibodies are directed against common surface proteins [113]. These surface proteins are also present in the surface of phase I Coxiella burnetii, but seem to be shielded by the long phase I LPS [105]. This antigenic variation is very important in serology and supports the diagnosis 
for the differentiation between acute and chronic $Q$ fever in humans $[114,115]$.

\section{Intracellular cycle and virulence's factors}

Histopathological analysis on Coxiella burnetii has identified monocytes and macrophages as the primary infection sites, but epithelial and endothelial cell infection has also been evident $[97,117]$. During infection, Coxiella burnetii is attached to macrophages by $a_{v} \beta_{3}$ Integrin, which triggers phagocytosis of the bacterium by an Actin-dependent mechanism [118]. The bacterium will then divert phagocytosis to its advantage. The nascent vacuole containing Coxiella (VCC) acquires the RAB5 GTPase as soon as 5 minutes after internalization. This GTPase stimulates the fusion of the VCC with early endosomes, resulting in acidification up to $\mathrm{pH}$ 5.4 and acquisition of the early endosomal marker protein, EEA1, which is characteristic of phagosomal development normal. However, unlike phagosomes, the VCC also acquires autophagosomal markers LC3 (Microtubule-associated protein Light-Chain 3). The maturation of the VCC causes it to lose RAB5 and EEA1 and acquire RAB7 GTPase and the membrane glycoprotein associated with the lysosome, LAMP1, 40 to 60 minutes after internalisation. This results in acidification up to a $\mathrm{pH}$ of 5 . These phenomena are also characteristic of normal phagosomal development. Two hours after internalization, lysosomal enzymes, including Cathepsin D, are beginning to accumulate in the VCC and the $\mathrm{pH}$ drops further to about 4.5. This process is significantly delayed compared to the normal phagolysosomal acquisition of Cathepsin D. The delay in the development of the VCC would seem to allow the conversion of small variants into large ones (SCV to LCV). From $8 \mathrm{~h}$ to 2 days after internalization, the VCC expands to occupy an increasingly large space in the cytoplasm of the host cell. This process is dependent on protein synthesis by the bacteria and involves the recruitment of GTPase RHO and RAB1B to the VCC membrane. The RHO GTPase is probably involved in the maintenance of this large vacuole, while the recruitment of RAB1B from the endoplasmic reticulum appears to facilitate acquisition of additional membranes to create this spacious CSS [119].

Phase II internalization is more efficient, resulting in better multiplication, thus explaining why phase II bacteria grow more rapidly than phase I, resulting in a shift from phase I to phase II in the laboratory [120].

More precisely, we note some differences between phase I and phase II in both pathway internalization and surviving in phagosomes. In phase I bacteria' attachment, it's involving $\alpha_{v} \beta_{3}$ Integrin, Integrin Associated Protein (IAP), and Toll-like Receptor 4. However, attachment of the phase II is mediated without TLR4 [120122]. In addition, phase II Coxiella burnetii maturation, involve the
Rab7, and acquiring Cathepsin D. Finally, phase I Coxiella burnetii bacteria are internalized and survive intracellular killing, whereas phase II bacteria are efficiently phagocytized and then killed in macrophages [120]. They have found that the addition of IgG antibodies from patients with endocarditis promotes the creation of large vacuoles. This finding may explain why large vacuoles in vivo are seen only during chronic infection [120].

\section{Pathogenesis and immune response to Coxiella burnetii}

In human infection is usually acquired from aerosols but infection by ingestion of contaminated dairy products is also possible. In animals too, the portal of entry is the oropharynx. The organism is highly infectious, with the infectious dose being as low as one organism [123]. Following inhalation, the organism must first invade before subsequently causing systemic infection. The alveolar macrophage has been proposed as the primary target. It has been suggested that one factor contributing to the attenuation of phase II forms versus phase I forms is the nature of the interaction between the organism with host cells [109].

After primary multiplication in the regional lymph nodes, an ensuing bacteraemia lasts for 5-7 days and the organism then localizes in the mammary glands and the placental of pregnant animals [106].

Immune control of Coxiella burnetii is T-cell dependent but does not lead to its eradication [122]. Coxiella burnetii can be found in apparently cured people, as well as in the dental pulp of experimentally infected and apparently cured guinea pigs [122,124]. Coxiella burnetii DNA can also be found in circulating monocytes or bone marrow of people infected months or years earlier [120]. Haematogenous spread results in the organism infection the liver, spleen, bone marrow, the reproductive tract and other organs. This is followed by the formation of granulomatous lesions in the liver and bone marrow and the development of endocarditis involving the aortic and mitral valve [106]. These granulomas are made possibly by the migration of monocytes through the vascular endothelium. A lipid vacuola forms the centre of the typical Q fever granuloma, it's surrounded by fibrinoid ring [33]. Few, if any isolated bacteria can be found in granuloma during the acute phase. TLR4 has a role in granuloma formation, since knouk-out mice deficient for this receptor have decreased number of these granuloma [122]. Specific immunoglobulins are secreted following infection. IgG is mainly directed against phase II antigen, whereas IgM is directed against both phase I and II cells [33]. Monocytes from convalescent patients are able to kill Coxiella burnetii. TLR4 modulates the cytokine (interferon ${ }_{\gamma}$ and tumour necrosis factor) response following acute infection [120]. 
During chronic $\mathrm{Q}$ fever the immune response is ineffective, and also may be harmful, causing leucocytoclastic vasculitis and glomerulonephritis. Coxiella burnetii continues multiply despite high concentrations of all three classes of antibodies (IgG, IgM and IgA) to phase I and phase II bacteria. Lymphocytes counts and CD4-toCD8 ratio are lowed [2]. Organ biopsies do not show granulomas but large vacuoles containing Coxiella burnetii can be detected in infected tissues such as heart valves and liver, and also in aneurysms. Monocytes from these patients are not able to kill Coxiella burnetii [31], and do not migrate through the endothelium [120].

In mice, both humoral and cellular immune responses are important in limiting the infection. Macrophages and other mononuclear cells are believed to be the major target cells during Coxiella burnetii infection [125]. T-cells are suggested to be critical for clearance of Coxiella burnetii after infection. B-cells are important for the prevention of tissues damage [108]. Antibodies can be detected as early as 14 days' post-inoculation for anti-Coxiella burnetii phase II antibodies and 21 days in the case of anti-Coxiella burnetii phase I antibodies. This is comparable to what was observed in goats. Upon infection, goats generate a phase I and phase II specific IgM and IgG response. After two weeks' post-infection, a strong phase II specific IgM and IgG antibody response can be detected while a less pronounced IgM anti-phase I response is present as well. IgG anti-phase I antibodies start to rise at 6 weeks' post-infection [105]. This information can help in the diagnosis of $\mathrm{Q}$ fever, understanding herd dynamics and will be helpful in improving vaccines.

Little is known about the pathogenesis of $\mathrm{Q}$ fever in domestic animals. Under laboratory conditions, Coxiella burnetii inoculation of both guinea pigs and mice results in systemic infection, including pneumonia, hepatitis and splenomegaly [126]. The severity of pathological changes depends on the strain. Splenomegaly is thought to be an indicator for the virulence of Coxiella burnetii strains in guinea pigs and mice [126]. Also the inoculation route seems to influence pathogenesis. In mice, intranasal inoculation is mainly associated with pneumonia, whereas intraperitoneal inoculation is mainly associated with hepato-spenomegaly [105]. In inoculated pregnant mice, Coxiella burnetii is abundantly present in both the foetal and maternal parts of the placenta [127]. In goats this is different [128]. In pregnant goats, the trophoblast of the allantochorion are target cells of Coxiella burnetii which multiplication occurs. Coxiella burnetii antigens are barely detected in adjacent maternal parts of the placenta. Sanchez in 2006, reported that in other maternal organs, Coxiella burnetii DNA, but no viable bacteria, can be found at some time points during pregnancy [129]. Recent research showed that infection route does not influence the pathogenesis and that Coxiella burnetii is not excreted during pregnancy [128]. This hampers the detection of infected pregnant goats. Recently, in 2017, Pellerin., et al. studied the Attachment of Coxiella burnetii to the zona pellucida of in vitro produced goat embryos, they clearly demonstrated that Coxiella burnetii, after in vitro infection at $10^{9}$ Coxiella $/ \mathrm{ml}$, stick strongly to the external part of the zona pellucida of in vitro without deap penetration; also Coxiella burnetii DNA was detected in all the eight batches of infected embryos after the 10 successive washing [130].

\section{Clinical presentations}

The clinical presentation of $\mathrm{Q}$ fever, including the proportion of people presenting with pneumonia and/or hepatitis, or other typical or atypical Q fever clinical signs, varies greatly from series to series and depends on the geographic origin of the infection. For example, pneumonia is more common than hepatitis in eastern Canada, while in southern Spain pneumonia is rare, and hepatitis is very common. In southern France, pneumonia is common and hepatitis very common [120].

\section{Primary infection}

Wide diversity of clinical symptoms is noted in Coxiella burnetii primary infection. The incubation period for the primary infection before the onset of symptoms can last from 2 to 3 weeks, and it depends on the size of the inoculum. In a large proportion of patients, the primary infection can be asymptomatic [120]. In other cases, pneumonia, hepatitis, or flu-like syndrome can be observed. The determinants of the symptomatology in Coxiella burnetii primary infection depend on host factors and on the strain involved. Age and sex ratio, have marked the stakes in the Netherlands epidemic, with symptomatic patients being significantly older and more often men than asymptomatic patients [131]. Children are also less frequently symptomatic than adults [132].

Clinical expressions of $\mathrm{Q}$ fever are often subclinical or extremely mild. For instance, during a $Q$ fever outbreak in Switzerland in 1987 , of the 415 patients diagnosed with $Q$ fever, 224 were seropositive but asymptomatic (54\%) and only $2 \%$ of those affected were hospitalized.

\section{Acute infection}

During acute $Q$ fever, the incubation is ranging from 14 to 39 days, and its expression depends widely to hosts factors. Thereby, the clinical signs vary greatly from patient to patient, where the immune-compromising patients express the disease more than others. In the Netherlands, the recent acute $Q$ fever outbreak showed a mortality rate of $1.2 \%$ within approximately 1 month after hos- 
pitalization of patients. All lethal cases suffered severe underlying medical conditions [133]. The notification criteria established in The Netherlands in 2010, for the laboratory diagnosis of acute $Q$ fever, is as following: a positive Coxiella burnetii specific PCR, IgM phase II antibodies, and fourfold increase of the IgG phase II antibodies titre. Distinctively, four major presentations are detailed. These are as follow;

\section{Isolated febrile syndrome}

In acute $\mathrm{Q}$ fever with isolated febrile syndrome (flu-like illness), additionally to the sudden onset of high fever (high grade fever, $40^{\circ} \mathrm{C}$ ) which is the predominant sign, other symptom can be established, as myalgia and headache, mostly retro-orbital. The fever can last for more than 15 days [120,134]. In Spain, 21\% of Q fever episodes presented febrile syndrome lasting for more than one week and less than three weeks [135], also in the recent Netherlands $Q$ fever outbreak, it was the most frequent sign among the affected patient. This nonspecific presentation is misleading and supports the fact that clinicians should include screening for $C$. burnetii primary infection in the presence of an isolated fever of unknown origin [104].

\section{Respiratory illness}

Atypical pneumonia is one of the most commonly recognized forms of acute $\mathrm{Q}$ fever, which we find in $15 \%, 82 \%, 33 \%, 22 \%$ of patients with immunosuppression, fever, headaches, and myalgia respectively $[120,135]$. The duration of symptoms varies from 10 to 90 days. Moreover, the prevalence of pneumonia during the primary infection is highly variable. It's considered as the major manifestation of acute $Q$ fever in Spain, Canada, Nova Scotia, Switzerland, and Cayenne. In this later country, in French Guiana, Coxiella burnetii MST 17 is responsible for the highest rate of community-acquired pneumonia in the world (around 40\%) [92]. Patients generally present non-productive cough, minimal auscultatory abnormalitie, but some patient present with acute respiratory distress, also nonspecific on the chest radiograph [135].

\section{Hepatitis}

In $Q$ fever endemic countries, hepatitis is more frequent than pneumonia. Such as France, Spain, Portugal, Taiwan [104]. Patients presenting $2 \%, 98 \%, 61 \%$ and $44 \%$ of immunosuppression, fever, headaches, and myalgia respectively, presenting also hepatitis [120]. Three major forms of hepatitis may be encountered: an infectious hepatitis-like form of hepatitis with heapatomegaly but seldom with jaundice, clinically asymptomatic hepatitis, and prolonged fever of unknown origin with characteristics granulomas on liver biopsy [135].

Other accompanying findings are anorexia, vomiting, and sometimes diarrhea and painful hepatomegaly $[92,104]$, also hyperbili- rubinemia which was found in $37 \%$ of cases in Taiwan [136]. In developing countries where coinfection with viral hepatitis is high, clinical manifestations of Coxiella burnetii hepatitis do not seem to be more severe. Fatal cases due to hepatic insufficiency are very rare and have been reported in a child, or in patients with cancer or alcoholism [104].

\section{Other acute $Q$ fever manifestation}

Other clinical aspects of acute $Q$ fever may occur, and its manifestation depends of the strain's virulence and host's immunity. In a case of a 41-year-old male, from USA, complaining of body aches, fever, nausea, malaise, bilateral knee pain, and vomiting. The Clinical examination revealed a notable erythematous blanching rash all over his body, positive serologic testing for Coxiella burnetii was confirmed, additionally the skin biopsy of the rash lesion, showed neutrophilic inflammatory destruction of small vessels with extravasation of red cells, nuclear dusting, and fibrinoid necrosis of the blood vessels, which remains specific for Leukocytoclastic vasculitis, this case confirms the variation of $Q$ Fever expression from a case to another [208]. Basically, we can classify these Q fever manifestation as following:

- Cardiac involvement: Pericarditis and myocarditis, are each found in $1 \%$ of cases, while myocarditis is frequently fatal [120]. Furthermore, acute endocarditis was observed in $\mathrm{Q}$ fever primary infection associated with high level IgG antibodies anti-cardiolipin (aCL) without any valvular Heart Disease (VHD), typically, the vegetation's were localized in the aortic valve [104]. The pathophysiological scenario for this new entity would be that $C$. burnetii primary infection causes an explosive secretion of autoantibodies, including IgG aCL, causing autoimmune valvular lesions [104].

- Neurological signs: Apart from headache, which is a common sign in acute $Q$ fever, revealing a possible neurological tropism of the bacterium. Consequently, aseptic meningitis and/or encephalitis, may occur in $0.2 \%$ to $1.3 \%$ of patients with $\mathrm{Q}$ fever, which are rarely accompanied by seizures and coma [135]. Cerebrospinal fluid (CSF) findings show lymphocytic meningitis. This neurological involvement could be caused by the immunological disorder following the bacterium invasion, resulting in sensory neuropathy or Guillain-Barre syndrome [137,138].

- Dermatological signs: Dermatological lesions are more common than generally thought, ranging from $1 \%$ to $9 \%$ of patients with acute $Q$ fever, it consists mainly of transient punctiform rashes, maculopapular eruptions, vesicular exanthema, and more rarely, erythema nodosum $[104,120,135]$. 
- $\quad$ Rare acute $\mathbf{Q}$ Fever clinical manifestations: Many other acute $Q$ fever presentations were found. Old rapports showed a typical "doughnut" or "fibrin ring" granuloma in biopsy specimens of bone marrow, during Coxiella burnetii primary infection, then a case of bone marrow necrosis was reported too [104]. In addition, uncommon manifestations of acute Q fever have been described, such as acute lymphadentis [139], cholecystitis [140], haemolytic anaemia, pancreatitis, lymphadenopathy mimicking lymphoma, and splenic rupture [135].

\section{Chronic infection}

Chronic $\mathrm{Q}$ fever can develop from a primary infection in about $1 \%$ to $5 \%$ of patients, whom differ from those with acute disease in age, predisposing conditions, clinical and laboratory findings, and evolution. It was initially described as lasting for more than 6 months after the onset, and can become manifest years after the initial infection $[105,135]$. Typically, the heart is the most commonly involved organ, followed by arteries, bones, and liver. Clinical symptoms include non-specific fatigue, fever, weight loss, night sweats an hepato-splenomegaly as well as endocarditis in patients with underlying valvular damage or immunocompromised, (bicuspid aortic valve, minimal mitral insufficiency, mitral valve prolapse), $30 \%$ to $50 \%$ of them develop chronic endocarditis. Systematically, echocardiography in all patients with acute $\mathrm{Q}$ fever is recommended to exclude underlying cardiac lesions $[120,141]$. Clinically, the disease usually presents as a subacute or acute blood culture-negative endocarditis [135], and it's undistinguishable from acute endocarditis, since fever is frequently recurrent or absent, and vegetations may be difficult to detect by echocardiography [120]. Q fever endocarditis is the most frequently reported form of persistent $C$. burnetii infection in the literature, its prevalence ranging from 3\% to $10 \%$ in England, France, Brazil, and Thailand [29,135,142,143]. In Africa, it represents from $1 \%$ to $3 \%$ of infective endocarditis in cohort studies [61]. However, its prevalence is probably underestimated in most developing countries, where microbiological tools for diagnosis are lacking. Other manifestations of chronic $Q$ fever include infections of aneurysms or vascular draft, osteoarthritis and osteomyelitis [135].

In 2012, Wegdam-Blans., et al. [141], established the Dutch Q Fever Consensus Group, in order to classify and organize better chronic $\mathrm{Q}$ fever diagnosis. The Consensus has been classified into three categories by three "P", Proven chronic $Q$ fever, Probable chronic $\mathrm{Q}$ fever, and Possible Chronic $\mathrm{Q}$ fever.

\section{Proven chronic $\mathbf{Q}$ fever}

Positive Coxiella burnetii PCR in blood or tissue or IFA titer of 1:1,024 for Coxiella burnetii phase I IgG, and Definite endocarditis according to the modified Duke criteria or Proven large-vessel or prosthetic infection by imaging studies (18 F-FDG PET, CT, MRI, or AUS).

\section{Probable chronic $Q$ fever}

IFA titer of 1:1,024 for Coxiella burnetii phase I IgG and one or more of the following criteria: Valvulopathy not meeting the major criteria of the modified Duke criteria; Known aneurysm and/ or vascular or cardiac valve prosthesis without signs of infection by means of TEE/TTE, 18 F-FDG PET, CT, MRI, or abdominal Doppler ultrasound; Suspected osteomyelitis or hepatitis as manifestation of chronic Q fever; Pregnancy; Symptoms and signs of chronic infection such as fever, weight loss, and night sweats, hepatosplenomegaly, persistent elevated ESR and CRP; Granulomatous tissue inflammation, proven by histological examination Immunocompromised state.

\section{Possible chronic Q fever}

IFA titer of 1:1,024 for Coxiella burnetii phase I IgG without manifestations meeting the criteria proven or probable chronic $Q$ fever. (MRI, magnetic resonance imaging; AUS, abdominal ultrasonography; ESR, erythrocyte sedimentation rate).

Both laboratory techniques (PCR, Coxiella burnetii phase I IgG titers) used in diagnosis of chronic Q Fever, have drawbacks; PCR on blood has a low sensitivity and the cut-off values of anti-Coxiella burnetii phase I to distinguish past from chronic infection, are still debated, and are either not sensitive or specific enough [209].

\section{Infection during pregnancy}

Both acute and chronic $\mathrm{Q}$ fever have been described during pregnancy. In mammals, Coxiella burnetii undergoes reactivation during pregnancy and thus is responsible for higher rates of abortion, prematurity, a low birth weight [135], likewise in humans, primary infection in pregnant women, whether or not symptomatic, may be followed by the same poor outcomes, mainly when Coxiella burnetii infection occurs during the first trimester [142,144]. The foetus may be infected during pregnancy. Furthermore, $Q$ fever may become chronic after delivery and be associated with recurrent miscarriages [120]. Coxiella burnetii has been isolated from the placenta of a woman who became pregnant $\mathbf{2}$ years after an episode of acute infection. Clinically, $\mathrm{Q}$ fever disease during pregnancy is most often asymptomatic [145], which lead to complicate more the course of the disease with utero fetal death, placentitis, thrombocythopenia. After invasion of the pregnant uterus and initial localization in the placenta, active Coxiella burnetii infections may hypothetically spread to the foetus hematogenously or by the amniotic-oral route and thereby compromise the foetus [206]. In order to investigate Coxiella burnetii in the precolostral blood samples in stillborn calves, Freick., et al. in 2017, sampled 56 stillborn calves, they demonstrated the presence of $7.1 \%$ of positive samples 
for Coxiella burnetii DNA, and 1.8\% sera were positive too for antiCoxiella antibodies by ELISA, these results prove the coxiellaemia and precolostral seroconversion occurred sporadically in stillborn calves from this endemically infected herds [207]. Seroprevalence studies in pregnant women show very variable rates in areas of endemicity: $0.15 \%$ in Marseille- Franc, $3.8 \%$ in Canada, and $4.6 \%$ in London, United Kingdom, 47\% in Denmark, and 9\% in the recent Netherlands outbreak [91,146-149]. In 2014, a meta-analysis of 136 cases and 7 population-based studies confirmed that seropositivity and untreated $Q$ fever during pregnancy, are associated with foetal death, and antibiotic treatment prevents this complication [150]. Moreover, genotypes from different geographical areas could induce different rates of obstetrical complications, which was suggested by Angelakis., et al. in 2013, when they reported Coxiella burnetii strains harboring the QpDV plasmid were associated with an increased risk of abortion [151].

\section{Post-Q Fever fatigue syndrome (QFS)}

In other hand, we have to pay more attention to the QFS, which is another long-term presentation of Q fever. In QFS patients Coxiella burnetii cannot be detected, and antibodies levels against the bacteria are low or negligible, these findings are completely upset in chronic Q fever. Symptoms of QFS include prolonged fatigue, arthralgia, myalgia, blurred vision and enlarged painful lymph node [33].

\section{Genomic aspects.}

In 2003, Seshadri., et al. sequenced the whole genome of Coxiella burnetii Nine Mile strain, this strain was isolated from ticks in Montana in 1935 and its genome is composed of 1,995,275 pb [94]. In addition, in 2007, the genome of Henzerling strain RSA 331, was isolated from the blood of an infected patient in northern Italy in 1945 [152]. Then, 3 other strains were sequenced, these are "K" and "G" isolates of chronic human endocarditis and the "Dugway" isolate of rodents, naturally attenuated [153].

As an intracellular pathogen, the most important factor for natural selection of Coxiella burnetii could be the interaction with its specific hosts niches. Genome reduction and the presence of mobile genetic elements and virulence related peudo-genes throughout the genome are predicted to be specific genome manifestations of the obligate intracellular life cycle of this pathogen [154]. Hence, a comparison of Coxiella burnetii genome sequences with specific emphasize on genes involved in pathogen-host (cell) interactions or modulation thereof, many shed light on adaptation mechanisms of Coxiella burnetii to various host species [154]. Previous studies have shown that Coxiella burnetii isolates differed respect to their plasmid type (QpH1, QpRs, QpDG, and QpDV), and lipopolysaccharide profiles [155]. Coxiella burnetii strains with a different genotypic profile can infect a variable range of host species with a different efficiency. For example, the CbNL01 genotype strains are predominantly strains in goats and in humans, whereas the CbNL12 genotype strains are commonly found in cattle and hardly in goats and humans [156].

\section{Coxiella burnetii genotyping}

Genotyping of bacteria is a key tool in the understanding of the epidemiology of infectious diseases. With regard to a zoonosis like $\mathrm{Q}$ fever, it is of tremendous importance, helping to find the animal source of human outbreaks. Currently, the three main discriminant genotyping methods used are multiple- locus Variable-Number Tandem Repeat (VNTR) analysis (MLVA), Multispacer Sequence Typing (MST), and Single Nucleotide Polymorphism (SNP) genotyping.

\section{VNTR-MLVA genotyping}

VNTR-MLVA genotyping was established by Svraka., et al. who amplified VNTR sequences from 21 Coxiella burnetii isolates [157]. They identified five main clusters and nine MLVA types. ArricauBouvery., et al. then analyzed 42 isolates and found 36 MLVA types. They proposed using two panels of markers to have a better discriminatory power [158]. However, MLVA is based on the analysis of relatively unstable repetitive DNA elements and can produce results that are too discriminatory. Moreover, it significantly lacks inter-laboratory reproducibility [104].

\section{MST genotyping and "geotyping"}

MST genotyping was introduced by Glazunova., et al. who identified 10 highly variable spacers located between ORFs [155]. This typing method identified 30 different genotypes and three monophyletic groups among 173 Coxiella burnetii isolates. These groups were partially correlated with plasmid types. The first group contained strains with the QpDV or QpRS plasmid, the second contained only strains with the QpH1 plasmid, and the third group contained plasmidless strains or strains with QpH1. This method is very discriminant and has been used most frequently in different studies around the world. MST genotyping helps to trace the spread of Coxiella burnetii from one region to another and from animal reservoirs to humans. Some MSTs are present across the five continents, whereas others are very specific to epidemic situations [104].

\section{SNP genotyping}

SNP genotyping was developed by a Dutch team during the outbreak in the Netherlands to provide a method directly applicable to animal and human samples without the need for enrichment by a culture step [159]. Ten discriminatory SNPs were selected using five Coxiella burnetii whole-genome sequences available in GenBank. (RSA493, RSA331, CbuG_Q212, Cbuk_Q154, and Dugway) [104]. 


\section{Diagnosis of Q fever disease}

In order to diagnose the $\mathrm{Q}$ fever, and identify the presence or not of Coxiella burnetii in samples specimens, several methods and technics are involved; each one of them differ with its sensitivity, specificity, and the target searched (DNA, immunoglobulins....).

\section{Nonspecific laboratory $\mathbf{Q}$ fever diagnosis}

Non-specific methods can be discussed when looking for the repercussion and effect of the presence of the bacterium on the heamatopoietic systems, the alteration of other functions, and also the corresponding hormonal fluctuations. knowing that $\mathrm{Q}$ fever gives a typical profile on all affected functions and systems.

\section{Acute $\mathbf{Q}$ fever}

The leukocyte count in patients with acute $Q$ fever is usually normal. However, $25 \%$ of patients have an elevated leukocyte count, ranging from $14 \times 10^{9}$ to $21 \times 10^{9} /$ liter. The erythrocyte sedimentation rate may be elevated. Thrombocytopenia is noted in $25 \%$ of patients. Liver enzyme levels are elevated in as many as $85 \%$ of patients. The increase in transaminase levels is usually moderate, ranging from 2 to 10 times normal values. During an episode of prolonged fever, the association of a normal leukocyte count, thrombocytopenia, and elevated hepatic enzyme levels are evocative of $\mathrm{Q}$ fever. However, thrombocytosis ( $>400 \times 10^{9}$ liter) may be encountered during convalescence. Twenty percent of patients have an elevated creatine phosphokinase level. In $Q$ fever meningoencephalitis, a mild lymphocytic pleiocytosis is frequently noted in the spinal fluid [135]. Furthermore, a variety of autoantibodies have been described in acute $Q$ fever, including antimitochondrial antibodies, and anti-smooth muscle antibodies [135].

\section{Chronic Q Fever}

In $\mathrm{Q}$ fever endocarditis, the cell-mediated inflammatory response to Coxiella burnetii has an impact on clinical and biological manifestation. Such as, conventional blood cultures remain negative, usual inflammatory syndrome, anaemia, elevated erythrocyte sedimentation rate, and polyclonal hypergammaglobulinemia. The leukocyte count may be normal, increased, or decreased. Thrombocytopenia and elevated hepatic enzyme levels are commonly found. Renal involvement is common, characterized by an elevated creatinine level and microhematuria. Monoclonal immunoglobulins are rarely observed, whereas cryoglobulins are frequently found. Autoantibodies are also frequent in chronic $Q$ fever, particularly rheumatoid factor, anti-smooth muscle, or antinuclear antibodies. Antimitochondrial antibodies, circulating anticoagulant antibodies, and a positive Coombs' test may also be observed [135].

\section{Specific Q fever laboratory Diagnosis}

Additionally, to the clinical manifestations, the presence of the desired pathogen can be identified, either by its DNA or by its antigen-antibody reaction. The specific diagnosis is depending on the predominant symptoms, samples nature, sample quantity, and also to its storage conditions.

\section{Collection and storage of specimens}

Coxiella burnetii is a very infectious disease. Thus, only biosafety level 3 laboratories and experienced personnel should be allowed to manipulate contaminated specimens and cultivate this microorganism from clinical samples. Several human specimens are suitable for the detection of Coxiella burnetii, but their availability depends on the clinical presentation. DNA amplification may be performed from blood, cerebrospinal fluid, bone marrow, cardiac valve biopsy, vascular aneurysm or graft, bone biopsy, or liver biopsy specimens; milk; placenta; foetal specimens in case of an abortion; and cell culture supernatants. Blood should be collected on EDTA or sodium citrate, and the leukocyte layer should be saved for the amplification. Solid specimens should be kept frozen at $280^{\circ} \mathrm{C}$ before testing [135]

\section{Serology}

In the presence of symptoms suggestive of Coxiella burnetii infection, serology is the first-line diagnostic technique. The immune response induces the production of anti-phase II and anti-phase I antibodies [160]. Coxiella burnetii phase II antigen is obtained after several passages in cell cultures or eggs, and anti-phase II antibodies are predominant during primary infection. Coxiella burnetii phase I antigen is obtained from the spleens of infected mice, and anti-phase I antibodies are associated with persistent infection [135]. The phase II antibodies are detectable 7 to 15 days after the onset of clinical symptoms and decrease thereafter within 3 to 6 months [160]. Antibodies are detectable by the third week after infection in $90 \%$ of patients [135]. For that reason, two serum samples (one from the acute phase and one from the convalescent phase) should be analyzed. Cutoffs for a positive serological titer can vary between countries. Generally, titers of phase II IgG of $\geq 200$ and/or IgM of $\geq 50$ are considered significant for the diagnosis of primary Q fever infection [135,161], and phase II IgG titers tend to be higher than phase I IgG titers during primary infection [160]. Independently of the symptomatology, residual IgG antibody titers may be detectable for years and even for life [104]. Elevated phase I IgG titers (IgG I titer of $\geq 1: 800$ ) are associated with persistent $Q$ fever. Higher phase I IgG titers correlate with a higher positive predictive value (PPV) for the diagnosis of Coxiella burnetii endocarditis: a PPV of $37 \%$ was found for IgG I titers of $1 \geq: 800$, and this 
reached $75 \%$ for IgG I titers of $\geq 1: 6,400$ in a study from the reference centre in Marseille-France [29]. For that reason, investigation for persistent infection should be performed in the case of persistent high levels of phase I antibodies 6 months after completion of treatment.

\section{Serology methods}

Indirect immunofluorescence assay (IFA) is the reference method, but the complement fixation test (CFT) and ELISA are also used. Others techniques exist, such as Western blotting, microagglutination, and the indirect hemolysis test, but they remain anecdotal. To date, only IFA, CFT, and ELISA are commercially available. The advantage of ELISA is that it is easy to perform, interpretation is less subjective than for IFA and CFT, and automation is possible. This method is mentioned in the CDC case definition of acute and chronic Q fever [160]. The specificity, sensitivity, and positive predictive value vary according to the technique and the antigen used. Most reference laboratories have developed their own inhouse immunofluorescence assay. In the reference centre in IHU, Marseille-France, screening is performed with phase II antigen on serum diluted at 1:50 and 1:100 to detect total immunoglobulins (IgT) directed against Coxiella burnetii antigens [162]. For all positive screenings with IgT titers of $\geq 1: 100$, quantification detection of antibodies for the subclasses IgG, IgM, and IgA for both phase I and phase II is performed. The titration of IgM and IgA is performed after removal of IgG using a rheumatoid factor absorbent to eliminate false-positive results due to interference with this protein. Moreover, the sera are diluted in phosphate-buffered saline with $3 \%$ non-fat powdered milk to saturate the antigenic site and avoid a nonspecific fixation of antibodies. Sensitivity was assessed at $58.4 \%$ and specificity at $100 \%$ [162]. For sera with titers inferior to these cutoffs, the serology should be repeated within 10 to 15 days to confirm or rule out the diagnosis.

\section{Indirect immunofluorescence assay (IFA)}

In human medicine, the IFA adapted as a micro-immunofluorescenec technique is the current method for the serodiagnosis of $\mathrm{Q}$ fever. Briefly, both phase I and phase II Coxiella burnetii antigens are used; phase II antigen is obtained by growing Coxiella burnetii Nine Mile reference strain in cell culture, while phase I antigen is obtained from the spleen of laboratory animals inoculated with phase II Coxiella burnetii in cell culture. A few phase I cells may still be present in the phase II population and can be selected and propagated within animals. Antigen is diluted, dropped on the wells of a glass microscope slide, allowed to dry, and fixed with acetone [163]. In addition, antigen-spot slide wells may be purchased from a supplier providing the phase II form, or phase I and II forms of Coxiella burnetii. These can be adapted by replacing the human conjugate by a conjugate adapted to the animal species. Twofold dilutions of the serum under test are placed on immunofluorescence slides with wells previously coated with one or two antigens. If specific antibodies are present, they are fixed by the antigen on the slide. The complex is then detected by examination with a fluorescence microscope following the addition of the fluorescent conjugate recognising the species-specific immunoglobulins [163].

\section{IFA materials and reagents}

Microscope equipped for the fluorescence, humidified incubator, washing basin. Slides suitable for the antigen are necessary. The latter may be either prepared in the laboratory or purchased from a supplier. The method described is adapted from the BioMérieux kit, and is given as an example. Ready-to-use slides contain 12 wells per slide, each of $7 \mathrm{~mm}$ diameter, coated with phase II antigen obtained from culture on Vero cells and can be stored at $4^{\circ} \mathrm{C}$ or $-20^{\circ} \mathrm{C}$. Concentrated fluorescent conjugate, to be diluted when required with Phosphate-Buffered Saline (PBS) $+1 \%$ Evans blue at the dilution recommended by the manufacturer. PBS, buffered glycerine, Evans dye $1 \%$ solution.

\section{IFA test procedure}

- Inactivate the sera under test for 30 minutes at $56^{\circ} \mathrm{C}$, then dilute serially from $1 / 40$ to $1 / 64$ In PBS.

- $\quad$ Allow the previously antigen-coated slides to warm to room temperature. Do not touch the wells.

- $\quad$ Add $20 \mu \mathrm{l}$ of each serum dilution to the wells. Add negative and positive control sera. To one well, add $20 \mu \mathrm{l}$ of PBS to serve as antigen control.

- Incubate in humid chamber for $30 \mathrm{~min}$ at $37^{\circ} \mathrm{C}$. Wash the slide twice with PBS for 10 minutes each. Rinse with distilled water and air dry.

- $\quad$ Add to the wells, including the controls, $20 \mu \mathrm{l}$ of the conjugate directed against the appropriate species.

\section{IFA results' interpretation}

A positive reaction will consist of small brilliant points against a dark background. Verify that the conjugate by itself and negative control serum give a negative result (absence of small brilliants points). Nonspecific fluorescence usually takes the form of spots of irregular shape. The positive control must give the known titer with \pm one dilution [163].

\section{Molecular detection}

The ability to detect and quantify Coxiella burnetii DNA by real-time PCR has dramatically enhanced diagnostic and study approaches. Several PCR-based assays have been developed for the detection of Coxiella burnetii in clinical samples. The first standard 
PCR systems targeted sequences of different types of plasmids, the 16S-23S RNA, the superoxide dismutase gene, the com1 gene or the IS1111 repetitive elements in human or animal samples $[66,104,164]$. The detection limits of these different methods ranged from 10 to $10^{2}$ bacteria. Also, nested PCR systems have been proposed, but these methods lack specificity $[165,166]$. Real-time PCR or quantitative PCR (qPCR) is a less time-consuming technique than PCR and has the advantage of quantifying the amount of bacteria in clinical samples. Thus, this method has become the most frequently used PCR system for diagnosis. The qPCR system targeting IS1111 (a repetitive element which is present in about 20 copies in the Coxiella burnetii Nine Mile genome) is the most sensitive $[104,167]$. This qPCR can detect the bacterium in the sera of patients within the first 2 weeks of infection, when serology is not yet positive. It also allows detection of Coxiella burnetii DNA in the blood of patients with persistent Coxiella burnetii infection [168]. In the Netherlands, Schneeberger., et al. found Coxiella burnetii DNA in $10 \%$ of seronegative samples from patients with signs of primary infection, confirming the usefulness of this method in the first 2 weeks of infection [169].

Recently, we improved the sensitivity of the qPCR test targeting the IS1111 gene by concentrating DNA extracted from clinical samples by lyophilization. The detection limit of Coxiella burnetii DNA was 100 -fold lower in lyophilized sera (1 bacterium $/ \mathrm{ml}$ ) than in nonlyophilized sera (102 bacteria/ml). This strategy was tested in 73 sera from patients with primary Coxiella burnetii infection and 10 sera from endocarditis patients, in whom the IS1111 qPCR performed under the usual conditions remained negative. In patients presenting with primary $Q$ fever, we observed qPCR sensitivity gains of $44 \%$ for the seronegative sera and $30 \%$ for early seropositive sera after lyophilization. The sensitivity of qPCR was also higher in sera from patients with endocarditis, of whom 8/10 $(80 \%)$ were positive after lyophilisation [170].

\section{Culture}

The isolation of Coxiella burnetii can be achieved from a wide range of clinical samples, including old samples if they have been stored at $-80^{\circ} \mathrm{C}$ before cultivation. The shell vial technique is still the most frequently used method. A sample of $1 \mathrm{ml}$ of the clinical specimen is inoculated on HEL cell monolayers in shell vials. The shell vials are then centrifuged $\left(700^{\circ} g\right.$ at $\left.20^{\circ} \mathrm{C}\right)$ for $1 \mathrm{~h}$. Centrifugation allows better attachment and penetration of Coxiella burnetii inside cells. Infected cells are then incubated at $37^{\circ} \mathrm{C}$ in a $5 \% \mathrm{CO} 2-$ enriched atmosphere for 5 to 7 days. Gimenez or immunofluorescence staining is used for detection of the bacterium inside cells [104]

\section{New diagnostic tools}

Other new tools have shown their efficiency in the confirmation of $Q$ fever diagnosis. Such as the Immuno-PCR is an interesting method, combining the amplification power of PCR with the specificity and versatility of ELISA, allowing an improvement in sensitivity, its specificity was evaluated at $92 \%$. In addition, the detection of Coxiella burnetii-specific gamma interferon $\left(\mathrm{IFN}_{\gamma}\right)$ production has been proposed as a new diagnostic tool. The IFN production assay is performed after in vitro stimulation of whole blood with antigens from the Q-vax vaccine or the inactivated Nine Mile strain. The measurement of $\mathrm{IFN}_{\gamma}$ production is then performed using ELISA [104].

A rapid bio-optical sensor, that transduces the presence of the target DNA based on binding-induced changes in the refractive index on the waveguide surface in a label-free and real-time manner, with isothermal DNA amplification, this new diagnostic tool offers a rapid ( $<20 \mathrm{~min}$ ) one-step DNA Amplification/Detection method. The team researchers confirm the clinical sensitivity ( $>90 \%$ ) of the bio-optical sensor, they tested it for detecting Coxiella burnetii in 11 formalid-fixed paraffin-embedded liver biopsy samples acute Q Fever hepatitis patients, and in 16 blood plasma samples from patients in which Q Fever is the cause of unknown origin [213].

\section{Infections sources and excrétion routes}

It is believed that Coxiella burnetii is ubiquitous in the environment as was shown recently in a 3 years' study across the USA [171], where geographically diverse areas, both agricultural and urban, were sampled. The organism has reservoirs in wide range of wild and domestic animals, including mammals, birds and arthropods [172], although the true extent of the reservoirs is unknown. Traditionally, $\mathrm{Q}$ fever has been related to livestock, of greatest relevance to human disease are domestic ruminants, which are the most common source of human infections [109], therefore livestock-related occupations have been deemed to be a risk factor [173]. In recent years in Europe, $90 \%$ of cases of $Q$ fever listed have had as a source of contamination sheep and goat products [174]. Coxiella burnetii infection of livestock is termed coxiellosis, a chronic but often symptomless disease. The uterus and mammary glands are sites of chronic infection in females, and this is associated with abortions in goats and sheep, and infertility in cattle [109]. Pets including cats, rabbits, and dogs, have also been demonstrated to be potential sources of urban outbreaks. A study conducted in Canada, demonstrated that 6 to $20 \%$ of cats have anti-Coxiella burnetii antibodies. Consequently, cats are suspected as an important reservoir of Coxiella burnetii in urban areas. Wild rats have been suspected as an important reservoir in Great Britain [135]. 
Knowledge of the excretion of Coxiella burnetii from infected animals is crucial in understanding the transmission routes and risks of human infection. Mammals when infected, shed the desiccation-resistant organisms in urine, faeces, milk, and especially, birth products [135]. Reactivation of infection occurs in female mammals during pregnancy. At birth, in the placenta of infected animals, vast quantities of pathogen are found, with high concentrations of Coxiella burnetii are registered (up to $10^{\circ}$ bacteria per $g$ of tissue) [135]. However, recent experimental indicate that comparable numbers of Coxiella burnetii are also excreted during the birth of lively kids [128]. In goat herds, both in aborting and nonaborting goats, Coxiella burnetii DNA has been detected in faeces, vaginal mucus and/or milk [175]. In cattle, also variable excretion via faeces, vaginal mucus and milk has been reported, sometimes independent of an abortion history. Sixty-five per cent of cows seem to shed Coxiella burnetii by only one route, evenly distributed over the three routes. Cows that excrete Coxiella burnetii by all three routes seem scare [176].

Shedding Coxiella burnetii by the later routes coincides with its replication in epithelial (trophoblast) cells of the placenta, and those of the entry site (lung epithelium), also in the epithelial cells of gut and udder. Sobotta., et al. in 2017, showed that these cell lines in bovine hosts, exhibited different permissiveness for Coxiella burnetii, thus, the udder cells allowed the highest replication rates, the intestinal cells showed an enhanced susceptibility to invasion, and lung and placenta cells also internalized the bacteria [211].

Mediannikov in 2010, found that in rural Senegal, endemic areas, humans similar to other mammals may become chronic excretors of Coxiella burnetii via faeces and milk, the found rates of shedding are, however not high and may not be compared with those identified in domestic animal [66]. All these high pathogen concentrations, are released to the environment [109]. Therefore, $\mathrm{Q}$ fever is an occupational hazard. At greatest risk are persons in contact with farm animals, but also at risk are laboratory personnel who work with infected animals [135]. Farming can facilitate environmental spread, such transport of infected animals and the spreading of contaminated manure onto fields. As well as, with the environment stability of the organism, pose a difficulty in containing outbreaks, as has been noted in the recent outbreak in the Netherlands [177]. Tozer., et al. study's, in 2012, confirmed that Coxiella burnetii can be readily detected in the environment, where they elucidated PCR evidence in wildlife urine and faecal samples as well as soil and dust samples [178]. Q fever was previously associated with dry, dusty and windy conditions as illustrated in the French study by Tissot-Dupont., et al. [179]. Airborne propagation can take place over long distances. In Briançon, France, a study reported the role of helicopters in the spread of aerosols near a slaughterhouse [180]. Various epidemiological surveys estimate the distance of diffusion during human epidemics: $400 \mathrm{~m}$ in Germany, $5 \mathrm{~km}$ in the Netherlands, $18 \mathrm{~km}$ in the United Kingdom, and 40 km in France [179,181-183]. In France, these are the "Mistral" and the geography of the places which have been conducive to long-distance broadcasting. Bacteria can also be transported through channels other than air, such as manure spreading, for example [184]. Other factors, such as vegetation and soil moisture, also appear to play an important role in the bacterial dispersal [186]. In the Netherlands, a study has shown that the risk of infection was 30 times greater within a $2 \mathrm{~km}$ radius of the infection's source, with respect to a radius of $5 \mathrm{~km}$, during an outbreak, in a geographical area without natural obstacle and in low rainfall conditions and strong winds [182]. However, a recent study in North Queensland by Harris., et al. 2013, demonstrated that there was clear correlation with rainfall, with the highest number of cases occurring 3 months after peak rainfall. It was postulated that increased rainfall attracted increased numbers of wildlife due to the increase in vegetation associated with wet season and the subsequent drier period potentially resulted in the aerosolization of the pathogen [187].

A rang of arthropods, including ticks, have been shown to be able to be colonized via ingestion of contaminated blood feeds. These ticks release significant quantities of Coxiella burnetii in their faeces. While experimental transmission between guinea pigs has been avhieved via tick bite [109], arthropod vectors are not considered essential to the natural cycle of infection in livestock that live closely contact with other infected animals. However, ticks may play an important role in transmission in the wild, for example between birds [109,172]. In addition, Coxiella burnetii has been isolated from ticks, particularly in the Kangaroo-habituating Ambylomma triguttatum [118]; these results support the suggestion that wildlife may be potential reservoirs for humans. Furthermore, Banazis., et al. in 2009, have shown that Australian wildlife carry Coxiella burnetii. The study highlights that $33.5 \%$ of western grey Kangaroo serum samples tested positive for Coxiella burnetii antibody-ELISA and $12.25 \%$ of the tested western grey kangaroos had positive Coxiella burnetii DNA detected in faecal samples [189].

The route of infection determines, in part, the minimum inoculum size, the severity of the disease, and the clinical manifestations [190]. In human beings, infection results from inhalation of contaminated aerosols (amniotic fluid, placenta, contaminated wool/ dusts). Compared with aerosols, subcutaneous and intramuscular inoculation require a lower inoculum to cause disease. Aerosol exposure to Coxiella burnetii causes a variable proportion on infection in those exposed [190]. In experimental models in mice [191] and guinea pigs [192], it is clear that there is a link between the route of inoculation and the prominent histological lesions. The respiratory route is associated with pneumonia and the intraperitoneal route 
with hepatitis [193]. These findings cannot be extrapolated to natural infection in human beings but show that the route of infection may be one of the factors influencing clinical presentation [120]. Otherwise, the ingestion of raw milk infected with Coxiella burnetii, although it causes seroconversion, has never been clearly associated with a clinical disease in humans $[120,199]$. The analysis of dairy products in France has demonstrated the presence of Coxiella burnetii DNA but no viable bacteria [167]. There is no formal evidence of a food transmission. Sexual transmission of $\mathrm{Q}$ fever has been suspected in humans, and demonstrated in the mouse [135]. Sporadic cases of human-to-human transmission following contact with an infected parturient woman have been reported and have been suspected to occur by direct aerosol transmission, resulting in congenital infections, via intradermal inoculation, and via blood transfusion [135]. An infectious dose of 1 to 10 bacteria has been estimated using animal models after observation of the serological response and/or fever, and/or lesions in organs; these values have been observed in inoculated infections intraperitoneal, which does not meet the conditions natural [192].

In the figure 3, we summarized the different infection sources, excretion's routes, and transmission mode between species.

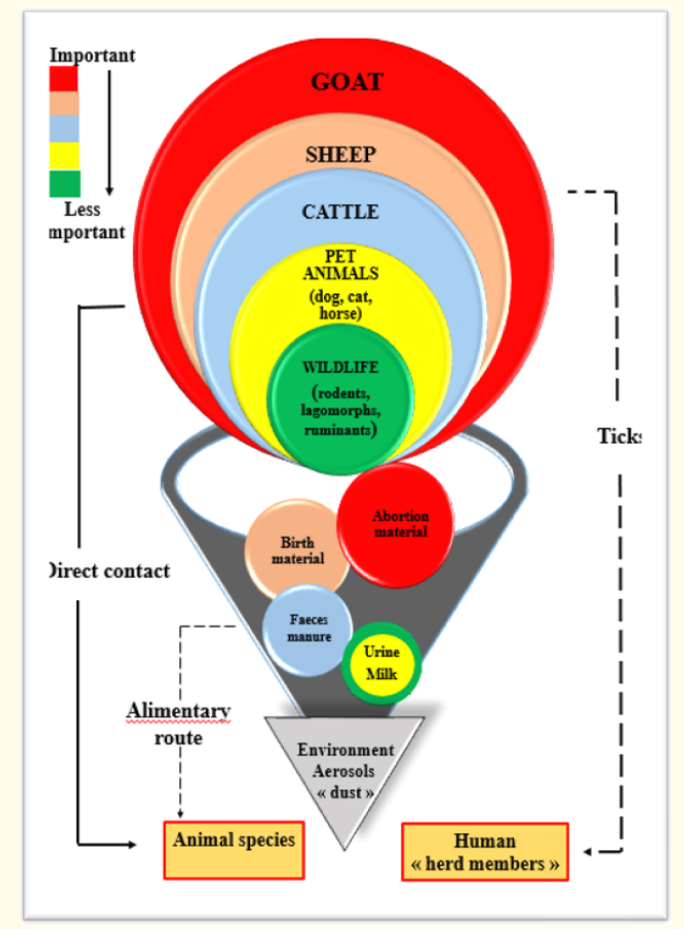

Figure 3: Transmission model for $Q$ fever. An overview of the possible transmission routes of Coxiella burnetii from the animal reservoir to the human (and animal) hosts. (Adapted from Roest et al, 2013).

\section{Bioterrorism threat}

When considering microbes as weapons they can simplistically be divided into lethal agents an incapacitating agents. Lethal agents, such Yersinia pestis induce an acute disease with ahigh associated mortality rate. Incapacitating agents make people ill enough that they cannot carry on with normal life for a period of time, but ultimately most people will recover [109]. Because one single organism of Coxiella burnetii can cause disease in a susceptible person, this pathogen has been classified on category B as incapacitating bioterrorism agent $[123,214]$.

Depending on the infective dose, Coxiella burnetii incubation period can be up to 3 weeks [4], with 4 days and 6 weeks representing the extremes [55]. Despite its low case-fatality rate, its ease of manufacture, its stability in the environment, and its ability to cause disease, Coxiella burnetii remains a high bioterrorism threat. $\mathrm{Q}$ fever is also part of military history, with some units having rates of over 30\% during the Second World War [190].

\section{Q fever treatment}

\section{Primary infection}

While $\mathrm{Q}$ fever symptomatic primary infection, it is recommended to initiate antibiotic treatment using doxycycline $(200 \mathrm{mg}$ per day). In case of doxycycline intolerance, minocycline, clarithromycin (500 mg twice daily), fluoroquinolones (ofloxacin $200 \mathrm{mg}$ three times a day or pefloxacin $400 \mathrm{mg}$ twice a day), and co-trimoxazole (160 mg trimethoprim and $800 \mathrm{mg}$ sulfamethoxazole twice daily) are alternatives $[194,195]$.

\section{Chronic infection (endocarditis)}

Combination between the antibiotic treatment for Coxiella burnetii endocarditis doxycycline $(200 \mathrm{mg} /$ day) with hydroxychloroquine (200 mg 3 times/day) is useful. Hydroxychloroquine is necessary to raise the $\mathrm{pH}$ in the pseudolysosomal vacuole to restore doxycycline activity $[196,197]$.

\section{Measures' control and vaccination}

Pasteurization and sterilization of milk remain the first step to take aiming to reduce the direct paths of contamination. when a livestock is suspected, limit the movement of personnel from one area to another, in order to limit the spread of the pathogen with tools and clothing contaminated by the bacteria, utensils and vehicles for animal transport must be disinfected and thoroughly washed down to avoid contamination of environment. Nevertheless, for the movement of animals from one sector to another, and especially to isolate sick subjects from clinically healthy ones, to facilitate epidemiological surveillance of the epidemic. In addition, the direction of dynamic winds must be discerned inside and outside livestock 
buildings to avoid the dispersion of contaminated aerosols. A control radius of about $10 \mathrm{~km}$ around outbreaks; should be applied to estimate dispersion via wind and surrounding climatic conditions. A regular test must be carried out on sheep and goats in research institutions, and culling of seropositive animals should be considered. All equipment that was in contact with contaminated livestock, or their abortion products or excreta, must be destroyed, especially to avoid the potential risk of high resistance of Coxiella burnetii in the external environment and contaminated material. In THE uk, Health Protection Agency guidelines [215], suggest the use of $2 \%$ formaldehyde, $1 \%$ Lysol, $5 \%$ hydrogenperoxide, $70 \%$ ethanol or $5 \%$ chloroform for decontamination of surfaces, and spills of contaminated material should be dealt with immediately using hypochlorite (5000 p.p.m, available chlorine). However, they state that is impossible to decontaminate large areas of a potentially contaminated environment [109].

The ideal vaccine against Coxiella burnetii would be based on antigens with good immunogenic potential, but which do not cause side effects such as reactivation of the infection or local reactions. In humans and animals, 2 types of vaccines are used: Whole Cell (WC) cell-based vaccines of Coxiella burnetii either in phase I or phase II, and vaccines based on bacterial walls extracted with chloroform methanol (CMR, chloroform methanol residue) [198]. In human, several vaccine types were manufactured, as live attenuated vaccine, corpuscular vaccine, vaccine chemically treated with chloroform methanol, soluble vaccine. Otherwise, in animals, only one effective vaccine exists, it's composed of corpuscular antigens; as the Coxevac ${ }^{\circledR}$ vaccine has proven its effectiveness in the prevention of abortions as well as reduction excretion of the germ in goats and cattle [198].

A soluble antigen complex produced by extraction with trichloroacetic acid from the highly purified Coxiella burnetii phase I strain Nine Mile. Consequently, they could identify 39 bacterial proteins from which 12 were recognized as immunoreactive, thus a new vaccination approach may take place in the future [212].

\section{Acknowledgment}

The authors thank all the medical staff of the Algerian National Centre of Infectious Diseases, EL-HADI FLICI Hospital; specially, Dr SAAD-DJABALLAH A, Pr ACHOUR N; for here wide contribution; also the Diagnosis Staff of the IHU-Marseille.

\section{Conflict of Interest}

None declared.

\section{Bibliography}

1. Kate D., et al. "The Epidemiology of Q Fever in England and Wales 2000-2015”. Veterinary Science 4 (2017): 28.

2. Sabatier F., et al. "CD4+ T-cell lymphopenia in Q fever endocarditis". Clinical and Diagnostic Laboratory Immunology 4 (1997): 89-92.

3. Linda M., et al. "Chronic $Q$ Fever in the Netherlands 5 Years after the Start of the $Q$ Fever Epidemic: Results from the Dutch Chronic Q Fever Database". Journal of Clinical Microbiology 52-5 (2014): 637-1643.

4. EH Derrick. "Q Fever, a New Fever Entity: Clinical Features, Diagnosis and Laboratory Investigation". Reviews of Infectious Diseases 5-4 (1983): 790-800.

5. FM Burnet and Mavis Freeman. "Experimental Studies of the Virus "Q" Fever". Reviews of Infectious Diseases 5-4 (1983): 800-808.

6. Gordon E., et al. "A Filter-Passing Infectious Agent Isolated from Ticks". PuBLIC Health Reports 53-52 (1938): 2259-2276.

7. RE Dyer. "Human Infection". PuBLIC Health Reports 53-52 (1938): 2277-2282.

8. Joseph E and McDade. Historical aspects of Q fever. Q fever: the disease (1990): 5-21.

9. Loïc Epelboin., et al. "Q Fever in French Guiana: Tip of the Iceberg or Epidemiological Exception?". Plos Neglected Tropical Diseases 2016.

10. Parker NR., et al. "Q fever". Lancet 367 (2006): 679-688.

11. Arricau-Bouvery N and Rodolakis A. "Is Q fever an emerging or re-emerging zoonosis?". Veterinary Research 36 (2005): 327-349.

12. Armengaud A., et al. "Urban outbreak of $Q$ fever, Briancon, France, to 1996". Eurosurveillance 2 (1997): 12-13.

13. Brouqui P., et al. "Q fever outbreak in homeless shelter". Emerging Infectious Diseases 2004 10: 1297-1299.

14. van Woerden HC., et al. "Q fever outbreak in industrial setting”. Emerging Infectious Diseases 10 (2004): 1282-1289. 
15. Steiner HA., et al. "Outbreak of Q fever among kitchen employees in an urban hospital". European Journal of Clinical Microbiology and Infectious Diseases 20 (2001): 898-900.

16. KA Bond., et al. "Review of 20 years of human acute $Q$ fever notifications in Victoria 1994-2013". Australian Veterinary Journal 96-6 (2018): 223-230.

17. KA Bond., et al. "One Health approach to controlling a $Q$ fever outbreak on an Australian goat farm". Epidemiology and Infection 144 (2016): 1129-1141.

18. Brett $\mathrm{N}$ Archer., et al. "Atypical outbreak of $\mathrm{Q}$ fever affecting low-risk residents of a remote rural town in New South Wales". CDI 42-2 (2017): E125-E132.

19. Jv Irons., et al. "Q Fever in The United States". JAMA 133-12 (1947): 819-820.

20. JH MCQuiston and JE. Childs. "Q Fever in Humans and Animals in the United States". Vector Borne and Zoonotic Diseases 2.3 (2002): 179-191.

21. Petros C., et al. "Chronic Q Fever in the United States". Journal of Clinical Microbiology (2006): 2283-2287.

22. Adam Bjork., et al. "First Reported Multistate Human Q Fever Outbreak in the United States 2011". Vector-Borne and Zoonotic Diseases 14 (2014).

23. Rare Q fever outbreak hits U.S medical tourists, 01/10/2015.

24. Honarmand H. "Q Fever: An old but still a poorly understood disease". Interdisciplinary Perspectives on Infectious Diseases (2012).

25. SN Shpynov., et al. "Comparison of genomes of Coxeilla burnetii strains using formal order analysis". New Microbes and New Infections 23 (2018): 86-92.

26. Roest HIJ., et al. "The Q fever epidemic in The Netherlands: history, onset, response and reflexion". Epidemiology and Infection 139 (2011): 1-12.

27. P Speelman. "The largest Q fever outbreak ever reported". The Netherlans Journal of medicine 68 (2010): 380-381.

28. Van Steenbergen JE., et al. "Een uitbraak van Q-koorts in Nederland - mogelijk verband met geiten". Nederlands Tijdschrift voor Geneeskunde 8 (2007): 151.
29. Diane Frankel., et al. "Q fever in France 1985-2009". Ermerging Infectious Diseases 17.3 (2011): 350-356.

30. Herve Tissot-Dupont., et al. "Hyperendemic Focus of Q Fever Related to Sheep and Wind". American Journal of Epidemiology 150-1(1999): 69-74.

31. Dellacasagrande J., et al. "Coxiella burnetii survives in monocytes from patients with $Q$ fever endocarditis: involvement of tumour necrosis factor". Infection and Immunity 68 (2000): $160-164$

32. G Dupuis., et al. "An Important Outbreak of Human Q Fever in a Swiss Alpine Valley". International Journal of Epidemiology 16.2 (1987): 282-287.

33. M Maurin and D Raoult. "Q Fever". Clinical Microbiology Reviews 12.4 (1999): 518-553.

34. Smith DL., et al. "A large Q fever outbreak in the West Midlands: clinical aspects". Respiratory Medicine 87 (1993): 509516.

35. Hawker., et al. "A large outbreak of Q fever in the West Midlands: windborne spread into a metropolitan area?". Communicable disease and public health 1 (1998): 180-187.

36. Hugo C., et al. "Q Fever Outbreak in Industrial Setting". Emerging Infectious Diseases 10.7 (2004): 1282-1289.

37. LE Wilson., et al. "Investigation of a Q Fever Outbreak in a Scottish Co-LocatedSlaughterhouse and Cutting Plant". Zoonoses Public Health 57 (2010): 493-498.

38. A Wallensten., et al. " $Q$ fever outbreak in Cheltenham, United Kingdom, in 2007 and the use of dispersion modelling to investigate the possibility of airborne spread". Surveillance and outbreak reports (2010).

39. C. Bellini., et al. " $\mathrm{Q}$ fever outbreak in the terraced vineyards of Lavaux, Switzerland". New Microbes and New Infections 2.4 (2014): 93-99.

40. Hurtado., et al. "Enviromental sampling coupled with realtime PCR and genotyping to investigate the source of $\mathrm{Q}$ fever outbreak in a work setting". Epidemiology and Infection (2017).

41. Sabahattin Payzin, "Epidemiological Investigations on Q Fever in Turkey". Bulletin of the World Health Organization 9 (1953): 553-559. 
42. Gozalan B., et al. "Is Q fever an emerging infection inTurkey?". La Revue de Santé de la Méditerranée orientale (2005): 384391.

43. Hellenbrand W., et al. "Changing epidemiology of Q fever in Germany 1947-1999”. Emerging Infectious Diseases journal 7.5 (2001): 789-796.

44. Berktas M., et al. "Seroprevalence of Coxiella burnetii antibodies in high risk groups in eastern Turkey". Turkiye Klinikleri Journal of Medical Sciences 3.1 (2011): 45-50.

45. Celebi B., et al. "Investigation of Q fever, Listeriosis, Toxoplasmosis and Cytic Echinococcosis seroprevalence in risk group". Turk Hij Den Biyol Derg 65.2 (2008): 67-73.

46. Aytekin Cikman., et al. "The seroprevalence of Coxiella burnetii in Erzincan, Turkey: Identification of the risk factors and their relationship with geographical featues". Journal of Vector Borne Diseases 54 (2017): 157-163.

47. Monika Szymanska-Czerwinska., et al. "Prevalence of Coxiella burnetii Infection in Humans Occupationally Exposed to Animals in Poland". Vector-Borne and Zoonotic Diseases 15.4 (2015): 261-267.

48. HS EL-Mahallawy., et al. "Q fever in China: a systematic review 1989-2013". Epidemiology and Infection 143 (2015): 673-681.

49. The Europrean Surveillance Sysytem "TESSy" (2016).

50. Blanc G., et al. A. Bull. Acad. Med (1947): 131-138.

51. Halawani E., El Dine KZ and El Fiki AYJ. Egyptian Medical Association 35 (1952): 339.

52. Martin M., et al. "The Geographeical Distribution of Q Fever". Bull. Wld Hlth Org 13(1955): 829-860.

53. Giroud P. et al. Bull. Acad. Mid 137 (1953): 29.

54. A Lacheheb and D Raoult. "Seroprevalence of Q-fever in Algeria". Clinical Microbiology and Infection (2009): 15-22.

55. Raoult D and Marrie T. "Q fever". Clinical Infectious Diseases 20 (1995): 489-495.

56. Meskini M., et al. "Seroepidemiology of Rickettsial infections in Morocco". European Journal of Epidemiology 11 (1995): 655-660.
57. Schelling E., et al. "Brucellosis and Q-fever seroprevalences of nomadic pastoralists and their livestock in Chad". Preventive Veterinary Medicine 61 (2003): 279 -293.

58. Potasman I., et al. "Outbreak of Q fever following a safari trip". Clinical Infectious Disease 30 (2000): 214 -215.

59. F Bellazreg N., et al. "Acute Q fever in hospitalised patients in Central Tunisia: report of 21 cases". European Society of Clinical Microbiology and Infectious Diseases 15 (2009): 138-139.

60. Kobbe R., et al. "Q fever in children, Ghana". Emerging Infectious Diseases 14 (2008): 344-346.

61. Sky Vanderburg., et al. "Epidemiology of Coxiella burnetii Infection in Africa: A OneHealth Systematic Review". PLOS Neglected Tropical Diseases 8.4 (2014): e2787.

62. Amin WF and Ahmed SO. "Detection of Coxiella burnetii in bovine milk samples using polymerase chain reaction". Assiut Veterinary Medical Journal 55 (2009): 23-31.

63. Kamga-Waladjo AR., et al. "Seroprevalence of Neospora caninum antibodies and its consequences for reproductive parameters in dairy cows from Dakar-Senegal, West Africa". Tropical Animal Health and Production 42 (2010): 953-959.

64. Scolamacchia F., et al. "Serological patterns of brucellosis, leptospirosis and Q fever in Bos indicus cattle in Cameroon". PLoS One 5 (2010): e8623.

65. Angelakis E., et al. "Coxiella burnetii-positive PCR in febrile patients in rural and urban Africa". International Journal of Infectious Diseases 28 (2014): 107-110.

66. Mediannikov 0., et al. "Coxiella burnetii in humans and ticks in rural Senegal". PLOS Neglected Tropical Diseases 4 (2010): e654.

67. Prabhu M., et al. "Q fever, spotted fever group, and typhus group rickettsioses among hospitalized febrile patients in northern Tanzania". Clinical Infectious Disease 53 (2011): e8e15.

68. Kamga-Waladjo AR., et al. "Seroprevalence of Neospora caninum antibodies and its consequences for reproductive parameters in dairy cows from Dakar-Senegal, West Africa". Tropical Animal Health and Production 42 (2010): 953-959.

69. Nahed HG and Khaled AAM. "Seroprevalence of Coxiella burnetii antibodiesamong farm animals and human contacts in Egypt". Journal of American Science 8 (2012): 619-621. 
70. Hussien MO., et al. "Seroprevalence of Q fever in goats in the Sudan". Veterinary World 5 (2012): 394-397.

71. Ghoneim N and Abdel-Moein K. "Seroprevalence of Coxiella burnetii antibodies among farm animals and human contacts in Egypt". Journal of American Science 8 (2012): 619-621.

72. Crump JA., et al. "Etiology of severe non-malaria febrile illness in Northern Tanzania: a prospective cohort study". PLOS Neglected Tropical Diseases 7 (2013): e2324.

73. Knobel DL., et al. "Coxiella burnetii in humans, domestic ruminants, and ticks in rural western Kenya". The American Journal of Tropical Medicine and Hygiene 88.3 (2013): 51358.

74. Ratmanov P., et al. "The correlation of $\mathrm{Q}$ fever and Coxiella burnetii DNA in household environments in rural Senegal". Vector-Borne and Zoonotic Diseases 13 (2013): 70-72.

75. Amina Bessas., et al. "Molecular evidence of vector-borne pathogens in dog and cat and their ectoparasites in Algiers, Algeria". Comparative Immunology, Microbiology and Infectious Diseases 45 (2016): 23-28.

76. H Khaled., et al. "Serological and Molecular evidence of $Q$ fever among small ruminant flocks in Algeria”. Comparative Immunology, Microbiology and Infectious Diseases 47 (2016): 19-25.

77. Atef Aouadi., et al. "Molecular evidence of tick-borne hemoprotozoan-parasites (Theileria ovis and Babesiaovis) and bacteria in ticks and blood from small ruminants in Northern Algeria". Comparative Immunology, Microbiology and Infectious Diseases 50 (2017): 34-39.

78. Mohammed H., et al. "Seroprevalence and risk factors for Coxiella burnetii, the causative agent of $Q$ fever in the dromedary camel (Camelus dromedarius) population in Algeria". Onderstepoort Journal of Veterinary Research 84.1 (2017).

79. Sulyok KM., et al. "Identification of novel Coxiella burnetii genotypes from Ethiopian ticks". PLoS One 9 (2014): e113213.

80. Bottieau E., et al. "Q fever after a journey in Syria: A diagnosis suggested by bone marrow biopsy". Acta Clinica Belgica 55 (2000): 30-33.

81. Esmaeili S., et al. "seroprevalence of brucellosis, leptospirosis, and Q fever among butchers and slaughterhouse workers in South-Eastern Iran". PLoS One 11 (2016): e0144953.
82. Faix DJ., et al. "Outbreak of Q fever among US military in western Iraq". Clinical Infectious Disease 46 (2008): e65-e68.

83. Esmaeili., et al. "Seropepidemiological survey of Q fever and brucellosis in Kurdistan province western Iran". Vector Borne Diseases 14 (2014): 41-45.

84. Mohhamed Hassan Kayedi., et al. "Seroepidemiological study of Q fever in Lorestan province, western Iran 2014". Iranian Journal of Microbiology 9.4 (2017): 213-218.

85. Ashraf Mohabbati Mobarez., et al. "Seroprevalence of Q fever among human and animal in Iran a Systematic review and meta-analysis". Plos Neglected Tropical Diseases 11.4 (2017): e0005521.

86. Garabedian GA., et al. "Q fever in Lebanon (Middle East)". American journal of hygiene 63 (1956): 313-318.

87. Mayssaa Fawaz Dabaja., et al. "The First Serological Study of Q Fever in Humans in Lebanon". Vector-Borne and Zoonotic Diseases (2018).

88. Ziva Amitai., et al. "A Large Q Fever Outbreak in an Urban School in Central Israel". Clinical Infectious Diseases 50.11 (2010): 1433-1438.

89. VM Vaidya., et al. "Comparison of PCR, Immunofluorescence Assay and Pathogen Isolation for Diagnosis of Q Fever in Humans with Spontaneous Abortions". Journal of Clinical Microbiology (2008): 2038-2044.

90. Loïc Epelboin., et al. "Q Fever in French Guiana: Tip of the Iceberg or Epidemiological Exception?". PLOS Neglected Tropical Diseases (2016).

91. van der Hoek W., et al. "Antibodies against Coxiella burnetii and pregnancy outcome during the 2007-2008 Q fever outbreaks in The Netherlands". BMC Infectious Diseases 11 (2011): 44 .

92. Edouard S., et al. "Comparison between emerging $Q$ fever in French Guiana and endemic Q fever in Marseille, France". The American Journal of Tropical Medicine and Hygiene 90.5 (2014): 915-919.

93. Gardon J., et al. "Suburban transmission of Q fever in French Guiana: evidence of a wild reservoir". The Journal of Infectious Diseases 184.3 (2001): 278-284.

94. Seshadri R., et al. "Complete genome sequence of the Q-fever pathogen Coxiella burnetiid". Proceedings of the National Academy of Sciences USA 100 (2003): 5455-5460. 
95. Gimenez DF. "Staining rickettsiae in yolk-sac cultures". Stain Technology 39 (1964): 135-140

96. Angelakis E and Raoult D. "Q fever". Veterinary Microbiology 140 (2010): 297-309.

97. Baca OG., et al. "Q fever and Coxiella burnetii: a model for host-parasite interactions". Microbiology Reviews 47 (1983): 127- 149.

98. Ben Amara., et al. "Coxiella burnetii, the agent of $\mathrm{Q}$ fever, replicates within trophoblasts and induces a unique transcriptional response". PLoS One 5 (2010): e15315.

99. La Scola B., et al. "Survival of Coxiella burnetii within freeliving amoeba Acanthamoeba castellanii". Clinical Microbiology and Infection 7 (2001): 75-79.

100. Bechah Y., et al. "Persistence of Coxiella burnetii, the agent of Q fever, in murine adipose tissue". PLoS One 9 (2014): e97503.

101. Voth DE and Heinzen RA. "Lounging in a lysosome: the intracellular lifestyle of Coxiella burnetiid". Cellular Microbiology 9 (2007): 829-840.

102. Sandoz KM., et al. "Transcriptional profiling of Coxiella burnetii reveals extensive cell wall remodeling in the small cell variant developmental form". PLoS One? 11 (2016): e0149957.

103. Sandoz KM., et al. "Developmental transitions of Coxiella burnetii grown in axenic media”. Journal of Microbiological Methods 96 (2014): 104 -110.

104. Carole Eldin., et al. "From Q Fever to Coxiella burnetii Infection: A Paradigm Change". Clinical Microbiology Reviews 30.1 (2017): 115-190.

105. Hendrik IJ Roest., et al. "Clinical microbiology of Coxiella burnetii and relevant aspects for the diagnosis abd control of the zoonotic disease Q fever". Veterinary Quarterly 33.3 (2013): 148-160.

106. Zerai Woldehiwet. "Q fever (coxiellosis): epidemiology and pathogenesis". Research in Veterinary Science (2004): 93100.

107. Vishwanath S., et al. "Lipopolysaccharide phase variation determines the complement-mediated serum susceptibility of Coxiella burnetii". Infection and Immunity 56 (1988): 40-44.
108. Andoh M., et al. "T cells are essential for bacterial clearance, and gamma interferon, tumor necrosis factor alpha, and $\mathrm{B}$ cells are crucial for disease development in Coxiella burnetii infection in mice". Immunology and Infections 75 (2007): 3245-3255.

109. PCF Oyston and C Davies. "Q fever: the neglected biothreat agent”. Journal of Medical Microbiology 60 (2011): 9-21.

110. Coleman SA., et al. "Proteome and antigen profiling of Coxiella burnetii development forms". Immunology and Infections 75 (2007): 290-298.

111. Narasaki CT., et al. "Lipopolysaccharide of Coxiella burnetiid". Advances in Experimental Medicine and Biology 984 (2012): 65-90.

112. Hotta A., et al. "Phase variation analysis of Coxiella burnetii during serial passage in cell culture by use of monoclonal antibodies". Immunology and Infections 70 (2002): 4747-4749.

113. Marrie TJ., et al. " $\mathrm{Q}$ fever areview and issues for the next century". International Journal of Antimicrobial Agents 8 (1997): $145-161$.

114. Million, M., et al. "Q fever: current diagnosis and treatment options”. Médecine et Maladies Infectieuses 39 (2009): 82-94.

115. Kampschreur LM., et al. "Chronic Q fever diagnosis -consensus guideline versus expert opinion". Emerging Infectious Diseases 21 (2015): 1183-1188.

116. Charles W., et al. "A human time dose response model for $Q$ fever". Epidemics (2017).

117. Russell-Lodrigue, K., et al. "Clinical and pathological changes in a guinea pig aerosol challenge model of acute $\mathrm{Q}$ fever". Infection and Immunity 7411 (2006): 6085-6091.

118. Baca OG., et al. "Entry of Coxiella burnetii into host cells". Acta Virologica 37 (1993): 143-155.

119. Van Schaik EJ., et al. "Molecular pathogenesis of the obligate intracellular bacterium Coxiella burnetiid". Nature Reviews Microbiology 11 (2013): 561-573.

120. D Raoult., et al. "Natural history and pathophysiology of Q fever". Lancet Infectious Diseases 52 (2005): 19-226.

121. Capo C., et al. "Subversion of monocyte functions by Coxiella burnetii: impairment of the cross-talk between $v \alpha \beta 3$ integrin and CR3". The Journal of Immunology 163 (1999): 6078-85. 
122. Honstettre A., et al. "Lipopolysaccharide from Coxiella burnetii is involved in bacterial phagocytosis, filamentous actin reorganization, and inflammatory responses through Toll-like receptor 4". The Journal of Immunology 172 (2004): 3695-703.

123. McQuiston JH., et al. "Q fever". Journal of the American Veterinary Medical Association 221 (2002): 796-799.

124. Aboudharam G., et al. "Culture of burnetiifrom the dental pulp of experimentally infected guinea pigs". Microbial Pathogenesis 36 (2004): 349-350.

125. Shannon JG and Heinzen RA. "Adaptive immunity to the obligate intracellular pathogen Coxiella burnetiid". Immunologic Research 43 (2009): 138-148.

126. Russell-Lodrigue KE., et al. "Coxiella burnetii isolates cause genogroup specific virulence in mouse and guinea pigs moldels of acute Q fever". Immunology and Infections 77 (2009): 5640-5650.

127. Baumgartner $\mathrm{W}$ and Bachmann $\mathrm{S}$. "Histological and immunecytochemical characterization of Coxiella burnetii associated lesions in the murine uterus and placenta". Immunology and Infections 3.60 (1992): 5232-5241.

128. Roest HIJ., et al. "Q fever in pregnant goats: pathogenesis and excretion of Coxiella burnetii”. PLoS One 7 (2012): 14.

129. Sanchez J., et al. "Experimental Coxiella burnetii infcetion in pregnant goats: a histhopathological and immunohistochemical study". Journal of Comparative Pathology 135 (2006): 108-115.

130. JL Pellerin., et al. "Attachment of Coxiella burnetii to the zona pellucida of in vitro produced goat Embryos". Theriogenology, an iternational journal of animal production 2017.

131. van Loenhout JAF, et al." Severely impaired health status of non-notified $Q$ fever patients leads to an underestimation of the true burden of disease". Epidemiology and Infection 143 (2015): $2580-2587$.

132. Maltezou HC and Raoult D. "Q fever in children". Lancet Infectious Diseases 2 (2002): 686-691.

133. Kampschreur LM., et al. "Acute $Q$ fever related in hospital mortality in the Netherlands". Netherlands Journal of Medicine 68 (2010): 408-413.
134. Marrie TJ. "Q fever pneumonia". Infectious Disease Clinics of North America 24 (2010): 27- 41.

135. Pierre-Edourad Fournier., et al. "Diagnosis pf Q Fever". Journal of Clinical Microbiology 36.7 (1998): 1823-1834.

136. Chang K., et al. "Acute hepatitis with or without jaundice: a predominant presentation of acute $\mathrm{Q}$ fever in southern Taiwan". Journal of Microbiology, Immunology and Infection 37 (2004): 103-108.

137. Skiba V and Barner KC. "Central nervous system manifestations of Q fever responsive to steroids". Military Medicine 174 (2009): 857- 859.

138. Rustscheff S. "Q fever as a cause of pure sensory polyneuropathy - the six-year itch: a follow-up of an indigenous Swedish case". Scand The Journal of Infectious Diseases 37 (2005): 949950.

139. Melenotte C., et al. "B-cell non-Hodgkin lymphoma linked to Coxiella burnetiid". Blood 127 (2016): 113-121.

140. Figtree M., et al. "Q fever cholecystitis in an unvaccinated butcher diagnosed by gallbladder polymerase chain reaction". Vector-Borne and Zoonotic Diseases 10 (2010): 421-423.

141. Wegdam-Blans MC., et al. "Chronic Q fever: review of the literature and a proposal of new diagnostic criteria". Journal of Infection 64 (2012): 247-259.

142. Watt G., et al. "Infective endocarditis in northeastern Thailand”. Emerging Infectious Diseases 20 (2014): 473- 476.

143. Correia MG., et al. "Diagnosis of blood culture-negative endocarditis and clinical comparison between blood culture-negative and blood culturepositive cases". Infection 44 (2016): 459-466.

144. Carcopino X., et al. "Q fever duringpregnancy: a cause of poor and maternal outcome". Annals of the New York Academy of Sciences 1166 (2009): 79-89.

145. Tissot-Dupont H., et al. "Role of sex, age, previous valve lesion, and pregnancy in the clinical expression and outcome of Q fever after a large outbreak". Clinical Infectious Disease 44 (2007): 232-237.

146. Rey D., et al. "Seroprevalence of antibodies to Coxiella burnetti among pregnant women in South Eastern France". European Journal of Obstetrics and Gynecology and Reproductive Biology 93 (2000): 151-156. 
147. Langley JM., et al. "Coxiella burnetii seropositivity in parturient women is associated with adverse pregnancy outcomes". American Journal of Obstetrics and Gynecology 189 (2003): $228-232$.

148. Baud D., et al. "Seroprevalence of Coxiella burnetii and Brucella abortus among pregnant women". Clinical Microbiology and Infection 15 (2009): 499 -501.

149. Nielsen SY., et al. "Prevalence of Coxiella burnetii in women exposed to livestock animals, Denmark 1996 to 2002". Eurosurveillance 18-28 (2013): 20528.

150. Million M., et al. "Revaluation of the risk of fetal death and malformation after Q fever". Clinical Infectious Disease 59 (2014): $256-260$.

151. Angelakis E., et al. "Q fever and pregnancy: disease, prevention, and strain specificity". European Journal of Clinical Microbiology and Infectious Diseases 32 (2013): 361-368.

152. CVI. Coxiella burnetii RSA 331. Craig Venter Institute. c. l., ed 2007.

153. Beare, P.A., et al. "Comparative genomics reveal extensive transposon-mediated genomic plasticity and diversity among potential effector proteins within the genus Coxiella". Infection and Immunity 77 (2009): 642-656.

154. Runa Kuley., et al. "Genome Plasticity and Polymorphisms in Critical Genes Correlate with Increased Virulence of Dutch Outbreak-Related Coxiella burnetiid". Frnotiers in Microbiology 8 (2017): 1526.

155. Olga Glazunova., et al. "Coxiella burnetii Genotyping”. Emerging Infectious Diseases journal 11.8 (2005): 1211-1217.

156. Roest HIJ., et al. "Molecular epidemiology of Coxiella burnetii from ruminants in $\mathrm{Q}$ fever outbreak, The Netherlands". Emerging Infectious Diseases 17 (2001): 668-675.

157. Svraka S., et al. "Establishment of a genotyping scheme for Coxiella burnetiid". FEMS Microbiology Letters 254 (2006): $268-274$.

158. Arricau-Bouvery N., et al. "Molecular characterization of Coxiella burnetii isolates by infrequent restriction site-PCR and MLVA typing". BMC Microbiology 6 (2006): 38.

159. Huijsmans CJJ., et al. "Single-nucleotide-polymorphism genotyping of Coxiella burnetii during a $\mathrm{Q}$ fever outbreak in The Netherlands". Applied and Environmental Microbiology 77(2011): 2051-2057.
160. Anderson A., et al. "Diagnosis and management of $Q$ feverUnited States 2013: recommendations from CDC and the Q Fever Working group". MMWR Recommendations and Reports 62 (2013): 1-23.

161. Dupont HT., et al. "Q fever serology: cutoff determination for microimmunofluorescence". Clinical and Diagnostic Laboratory Immunology 1 (1994): 189 -196.

162. Imbert $\mathrm{G}$ and La Scola B. "Diagnosis of $\mathrm{Q}$ fever using indirect microimmunofluorescence". Methods in Molecular Biology 345 (2006): 197-202.

163. OIE Terrestrial Manual (2010).

164. Stein A., et al. "Study of the $16 \mathrm{~S}-23 \mathrm{~S}$ ribosomal DNA internal spacer of Coxiella burnetiid". European Journal of Epidemiology 13 (1997): 471- 475.

165. Fenollar F., et al. "Molecular detection of Coxiella burnetii in the sera of patients with $Q$ fever endocarditis or vascular infection". Journal of Clinical Microbiology 42 (2004): 4919 4924.

166. Fenollar F and Raoult D. "Molecular genetic methods for the diagnosis of fastidious microorganisms". APMIS 112 (2004): 785- 807.

167. Eldin C., et al. "Coxiella burnetii DNA, but not viable bacteria, in dairy products in France". The American Journal of Tropical Medicine and Hygiene 88 (2013): 765-769.

168. Rolain J-M and Raoult D. "Molecular detection of Coxiella burnetii in blood and sera during Q fever". QJM 98 (2005): 615620.

169. Schneeberger PM., et al. "Real-time PCR with serum samples is indispensable for early diagnosis of acute $\mathrm{Q}$ fever". Clinical and Vaccine Immunology 17 (2010): 286 -290.

170. Edouard S and Raoult D. "Lyophilization to improve the sensitivity of qPCR for bacterial DNA detection in serum: The Q fever paradigm". Journal of Medical Microbiology 65 (2016): 462- 467.

171. Kersh GJ., et al. "Presence of Coxiella burnetii DNA in the environment of the United States 2006 to 2008". Applied and Environmental Microbiology 76 (2010): 4469-4475.

172. Raoult D. "Host factors in the severity of Q Fever". Annals of the New York Academy of Sciences 590 (1990): 33-38. 
173. M Garner, et al. "A Review of Q Fever in Australia 19911994". Australian and New Zealand Journal of Public Health 21 (1997): 722-730.

174. EFSA Panel on Animal Health and Welfare (AHAW). "Scientific Opinion on Q Fever". EFSA Journal 8(5) (2010): 1595.

175. Roest HIJ., et al. "Q fever in 2008 in The Netherlands and the expectations of 2009". Tijdschr Diergeneeskds 134 (2009): 300-303.

176. Guatteo R., et al. "Shedding routes of Coxiella burnetii in dairy cows: implications for detection and control". Veterinary Research 37 (2006): 827-833.

177. Enserink, M. "Questions abound in Q Fever explosion in the Netherlands". Science 2010 327: 266-267.

178. Tozer, et al. "Potential animal and environmental sources of Q fever infection for humans in Queensland". Zoonoses Public Health 61 (2014): 105-112.

179. H Tissot-Dupont., et al. "Wind in November, Q Fever in December". Emerging Infectious Diseases 10 (2004): 1264-1269.

180. Carrieri MP., et al. "Investigation of a slaughterhouserelated outbreak of Q fever in the French Alps". European Journal of Clinical Microbiology and Infectious Diseases 21 (2002): 1721.

181. Gilsdorf, A., et al. "Large Q fever outbreak due to sheep near residential areas, Germany 2005". Epidemiology and Infection 136 (2008): 1084-1087.

182. Schimmer, B., et al. "The use of a geographic information system to identify a dairy goat farm as the most likely source of an urban Q-fever outbreak". BMC Infectious Diseases 10 (2010): 69.

183. Hackert, VH., et al. "Q fever: single-point source outbreak with high attack rates and massive numbers of undetected infections across an entire region". Clinical Infectious Diseases 55 (2012): 1591-1599.

184. Berri M., et al. "Ovine manure used a garden fertiliser as a suspected source of human Q fever". Veterinary Record 153 (2003): 269-270.

185. Hermans, T., et al. "Landapplied goat manure as a source of human Q-fever in the Netherlands 2006-2010". PLoS One 9 (2014): e96607.
186. van der Hoek W., et al. "Q fever in the Netherlands: the role of local environmental conditions". International Journal of Environmental Health Research 21 (2011): 441-451.

187. P Harris, et al. "Acute $Q$ fever in northern Queensland: variation in incidence related to rainfall and geographical location". Epidemiology and Infection 141-5 (2013): 1034-1038.

188. NRParker., et al. “Q Fever”. Lancet 367 (2006): 679-688.

189. M. Benazis, et al. "A survey of Western Australian sheep, cattle and Kangaroos to determine the prevalence of Coxiella burnetiid". Veterinary Microbiology 143 (2010): 337-345.

190. Williams JC. Infectivity, virulence, and pathogenicity of Coxiellaburnetii for various hosts. In: Williams JC, Thompson HA, eds. $Q$ fever: the biology of Coxiella burnetii. Boca Raton, Florida: CRC Press (1991): 21-71.

191. Marrie TJ., et al. "Route of infectiondetermines the clinical manifestations of acute Q fever". The Journal of Infectious Diseases 173 (1996): 484-487.

192. La Scola B., et al. "Pathologic changes during acute Qfever: influence of the route of infection and size in infected guinea pigs". Infection and Immunity 65 (1997): 2443-47.

193. Leone M., et al. "Effect of sex on Coxiella burnetii infection: protective role of 17_-estradiol". The Journal of Infectious Diseases 189 (2004): 339-45.

194. Gikas A., et al. "In vitro susceptibility of Coxiella burnetii to trovafloxacin in comparison with susceptibilities to pefloxacin, ciprofloxacin, ofloxacin, doxycycline, and clarithromycin". Antimicrobial Agents and Chemotherapy 42 (1998): 27472748.

195. Gikas A., et al. "In vitro susceptibility of Coxiella burnetii to linezolid in comparison with its susceptibilities to quinolones, doxycycline, and clarithromycin". Antimicrobial Agents and Chemotherapy 45 (2001): 3276 -3278.

196. Raoult D., et al. "Bactericidal effect of doxycycline associated with lysosomotropic agents on Coxiella burnetii in P388D1 cells". Antimicrobial Agents and Chemotherapy 34 (1990): $1512-1514$

197. Maurin M., et al. "Phagolysosomal alkalinization and the bactericidal effect of antibiotics: The Coxiella burnetii paradigm". The Journal of Infectious Diseases 166 (1992): 1097-1102. 
198. Samira Boarbi., et al. "Coxiella burnetii, agent de la fièvre Q". Canadian Journal of Microbiology 62 (2016): 102-122.

199. Angelakis E., et al. "Q Fever". Veterinary Microbiology 140 (2010): 297-309.

200. Dorko E., et al. "Influence of the environ $\neg$ ment and occupational exposure on the occurrence of Q fever". Central European Journal of Public Health 20 (2012): 208-214.

201. Kováčová E., et al. "Suitability of various Coxาiella burnetii antigen preparations for detection of serum antibodies by various test". Acta Virologica 42 (1998): 365-368.

202. G Flores-Ramírez., et al. "Protein composition of the phase I Coxiella burnetii soluble antigen prepared by extraction with trichloroacetic acid". Acta virologica 61 (2017): 361 - 368.

203. Margarita Bolanos-Rivero., et al. "Detection of Coxiella burnetii DNA in Peridomestic and Wild Animals and Ticks in an Endemic Region (Canary Islands, Spain)". Vector-Borne and Zoonotic Diseases (2017).

204. A Joulié., et al. "Coxiella burnetii circulation in a naturally infected flock of sheep: individual follow-up of antibodies in serum and milk". American Society for Microbiology (2017).

205. Lindsay A., et al. "A case of Q fever after liver transplantation". Transplant Infectious Disease (2017): e12737.

206. Agerholm JS. "Coxiella burnetii associated reproductive disorders in domestic animals-a critical review". Acta Veterinaria Scandinavica 55 (2013): 13.

207. Markus Freick., et al. "Detection of Coxiella burnetii DNA and anti-Coxiella burnetii IgG antibodies in precolostral blood samples of stillborn calves in an endemically infected Holstein dairy herd". Folia Microbiologica (2017).

208. Stephen S., et al. "Leukocytoclastic vasculitis presenting in association with Coxiella burnetii (Q fever) a case report". Journal of Cutaneous Pathology 45.1(2018): 71-73.

209. Kampschreur LM., et al. "Microbiological challenges in the diagnosis of chronic $\mathrm{Q}$ fever". Clinical and Vaccine Immunology 19 (2012): 787-790.

210. Mostafa F N., et al. "Cross-sectional study for determining the prevalence of $\mathrm{Q}$ fever in small ruminants and humans at $\mathrm{El}$ Minya Governorate, Egypt". BMC Research Notes 1.10 (2017): 538.
211. Katharina Sobotta., et al. "Permissiveness of bovine epithelial cells from lung,intestine, placenta and udder for infection with Coxiella burnetiid". Veterinary Research 48 (2017): 23.

212. G Flores-Ramírez., et al. "Protein composition of the phase I Coxiella burnetii soluble antigen prepared by extraction with trichloroacetic acid". Acta virologica 61 (2017): 361-368.

213. Bonhan Koo., et al. "A rapid bio-optical sensor for diagnosing $Q$ fever in clinical specimens". Journal of Biophotonics 11.4 (2018): e201700167.

214. Centers for Disease Control and Prevention. Q fever. Atlanta: CDC 2003: CDC fact sheet.

215. www.hpa.org.uk/deliberate_accidental_releases/biological

\section{Volume 2 Issue 10 October 2019}

(C) All rights are reserved by Ghaoui $\mathrm{H}_{\text {., }}$ et al. 